\title{
Numerical model validation for mooring systems: Method and application for wave energy converters
}

\author{
Harnois V. ${ }^{1, *}$, Weller Sam D. ${ }^{1}$, Johanning L. ${ }^{1}$, Thies P. R. ${ }^{1}$, Le Boulluec Marc ${ }^{2}$, Le Roux Dominique ${ }^{2}$, \\ Soulé Veronique ${ }^{2}$, Ohana Jeremy ${ }^{2}$
}

${ }^{1}$ Univ Exeter, Coll Engn Math \& Phys Sci, Penryn TR10 9FE, Cornwall, England.

2 IFREMER, F-29280 Plouzane, France.

* Corresponding author : V. Harnois, email address : V.Harnois@exeter.ac.uk

S.Weller@exeter.ac.uk ; L.Johanning@exeter.ac.uk ; P.R.Thies@exeter.ac.uk ; Marc.Le.Boulluec@ifremer.fr ; Dominique.Le.Roux@ifremer.fr ; Jeremy.Ohana@ifremer.fr

\begin{abstract}
:
The design of wave energy mooring systems is challenging: overdesign incurs a significant cost penalty, underdesign may lead to a premature failure and incorrect design could reduce the power production. Consequently, compliant mooring systems are being developed for wave energy applications. This paper presents tank test results for a scale model of the buoy and mooring used at the SouthWest Mooring Test Facility (SWMTF), an offshore facility developed to conduct long-term sea trials for wave energy device moorings. A compliant three leg catenary mooring system using Nylon ropes in the water column is investigated. Preliminary static, quasi-static, decay, regular and irregular wave tests were conducted on the 1:5 scale model, using the Ifremer basin in Brest. A corresponding numerical model was developed with a time-domain mooring modelling tool, inputting hydrodynamic data from a radiation/diffraction potential modelling program. After the calibration of several hydrodynamic parameters, the numerical model demonstrated good agreement with the experiment. However, numerical results show large differences with the field test results, mainly because of unknowns in the anchor position. The methods and procedures presented will allow the effective validation of numerical models to enable the development of appropriate mooring systems in wave energy applications.
\end{abstract}

\section{Highlights}

- The numerical model of a mooring system has been calibrated. Tank tests of a mooring typical of a wave energy device have been conducted. Tank test results have been compared with field test results. Use of a stiffer rope does not significantly affect the tank test results. The radiation/diffraction potential analysis shows limitations for such tests.

Keywords : Wave energy converter, Tank tests, Numerical model, Highly dynamic mooring system, Fibre rope 
The survivability of a wave energy device is dependent on the structural integrity of the mooring system, which represents an estimated $5 \%$ of the cost of energy [1] and of the capital costs for a farm [2]. Total or partial failure of the mooring system may lead to the loss of the device. This risk must be balanced with the cost of an over-engineered design.

Wave energy mooring systems do have specific requirements [3]. In particular motion-dependent devices need to have compliant mooring lines to avoid large mooring loads or adverse effects on power production. This requirement can for example be satisfied by synthetic fibre ropes. At the same time the mooring system should limit the low-frequency horizontal motion of the floating body to avoid tension on the power cable or collisions between devices in an array, for example by providing restoring forces with a catenary mooring system. The chosen mooring system for a motiondependent wave energy device allows the floating structure to move in a highly dynamic way, which would usually not be desirable for a traditional oil and gas floating structure.

The main aim of early stage tank tests is often to validate concepts and to improve the performance of the Power Take-Off (PTO) system [4]. Consequently, the mooring system is commonly represented in a simplified form which does not significantly influence the behaviour of the PTO system [5] and/or the limited water depth in the tank does not allow the moored model to be scaled correctly [6]. However, it is crucial that the influence of the mooring system on PTO performance is taken into account at a more advanced stage in order to optimise the performances of the wave energy device. For example in [7] the power production for the DEXA wave energy device was compared for two types of mooring system: Catenary Anchor Leg Mooring (CALM) and spread mooring. Different catenary configurations-with different attachment points and/or the use of additional surface buoys were also compared in terms of power production in [8].

This paper draws on tank tests that were conducted using a scale model of the buoy and mooring used at the South West Mooring Test Facility (SWMTF). The methods used for these tank tests are methods which have been widely used by the offshore oil and gas industry and are still used to investigate a particular problem. In this study, the mooring is particularly compliant, allowing highly dynamic motions of the floating structure, especially in pitch. The SWMTF research is led by the Renewable Energy group at the University of Exeter and was initiated through funding provided through the Peninsula Research Institute for Marine Renewable Energy (PRIMaRE). This facility has been built to conduct long-term sea trials for the mooring systems of marine energy devices. It is installed in Falmouth Bay, Cornwall, UK, in a site with a water depth between 27 and $32.4 \mathrm{~m}$, depending on tidal elevation. This facility has been previously described in [9-11]. The highest observed significant wave height, $H_{S}$, was $3.5 \mathrm{~m}$ and the most frequent sea states were for $H_{S}$ equal to $0.8 \mathrm{~m}$ and peak period, $T_{p}$, equal to $6 \mathrm{~s}$. At the SWMTF, an instrumented surface buoy of mass $M=3250 \mathrm{~kg}$ is moored with a three catenary leg mooring system combining chains and nylon rope. The axial stiffness ( $E A$ with $E$ the Young's Modulus and $A$ the 
sectional area of the rope) of dry nylon rope used as part of the SWMTF mooring system was measured from tensiontension tests conducted using the Dynamic Marine Component (DMaC) facility at the University of Exeter [12]. For a range of harmonic loading regimes with mean loads and amplitudes not exceeding $1.0 \%$ and $0.6 \%$ respectively of the Minimum Breaking Load (MBL), the rope sample demonstrated axial stiffness values between 889-972 kN for oscillation periods ranging from 25 to $100 \mathrm{~s}$.

This paper is divided in 5 sections, including the introduction. Section 2 will describe the experimental set-up and the numerical modelling of the mooring system. Section 3 gives results from static and quasi-static tests, decay tests, as well as regular and irregular wave tests. The results are discussed in section 4 followed by a conclusion in section 5 .

\section{Experimental set-up and modelling of the mooring system}

This section describes the experimental set-up and the numerical modelling of the mooring system. The properties of the basin and its instrumentation are described, the choice of scale is explained, and the scaled properties of the buoy and its mooring are detailed. Finally, the inputs of the numerical model are defined.

\subsection{Experimental set-up}

The tank tests were performed in the Ifremer deep water wave basin in Brest, France. This tank uses sea water with a density of $1.026 \mathrm{~kg} / \mathrm{m}^{3}$ at $17.2^{\circ} \mathrm{C}$, and $35.6 \%$ salinity (averages based on three sample measurements during the test period using the method described by Sharqawy et al. [13]. The basin is $50 \mathrm{~m}$ long, $12.5 \mathrm{~m}$ wide and $10 \mathrm{~m}$ deep for the first three quarters of its length, where the model is installed. The wave generator is able to generate waves with maximum amplitude of $0.5 \mathrm{~m}$ and with periods from 0.8 to $3.5 \mathrm{~s}$. The mooring loads were recorded with axial load cells installed on the top of each mooring line. Six degree of freedom motions at the centre of gravity of the buoy were determined using a Qualysis $^{\mathrm{TM}}$ video motion tracking system with reflecting targets mounted on the top of the buoy (Fig. 1 (a)). Surface elevations were measured with servo wave gauges, installed as shown in Fig. 1 (b). All measured signals were time synchronised and recorded at $100 \mathrm{~Hz}$.

The scale of the model was determined by the dimensions of the tank, particularly its width. An initial full-scale static numerical investigation with Orcaflex ${ }^{\mathrm{TM}}$ was carried out to estimate the length of mooring line constantly resting on the seabed for a range of surge/sway $(+/-30 \mathrm{~m})$ and heave $(+/-15 \mathrm{~m})$ buoy motions. These motions were the largest observed motions during the sea trials of the SWMTF. The portion of mooring line which rests on the seabed during large displacements does not significantly interfere with the hydrodynamic behaviour of the system and can therefore be truncated. The results of this preliminary study indicated that a Froude model scale of 1:5 with a water depth of $5.95 \mathrm{~m}$ was feasible. A false floor was installed in the tank to achieve the desired water depth (Fig. 1 (c)). Truncated mooring lines were simplified and scaled (Table 1). For example, on the full scale SWMTF mooring, section 4 of the mooring line is made of a DN24 openlink chain and of a 9.5 tonnes shackle. In the scale model mooring, only a chain was used while taking into account the weight of the shackle. The drag and inertia coefficients for the mooring lines were taken from DNV standards [14] for the nylon lines and from the Orcaflex ${ }^{\mathrm{TM}}$ manual [15] for the chains. The axial stiffness of three samples extracted from the used model rope was quantified using tension testing equipment at Ifremer [16]. The yarns demonstrated axial stiffness values between 10.0 and $12.6 \mathrm{kN}$ when subjected to scaled (by N/Tex) loading using a $25 \mathrm{~s}$ oscillation period. An average value of $10.873 \mathrm{kN}$ was used in the numerical model, while the scaled value of the stiffness of the rope used at the SWMTF ranges between 7.1 and $7.8 \mathrm{kN}$.

The model was orientated with mooring lines 1 and 3 facing the wave symmetrically (Fig. 1 (b)), and all tests were carried out with a wave incidence angle equal to zero. Table 2, adapted from [17] gives details about the scale model properties, and the differences between the theoretical scaled values and the measured scaled values. Fig. 1 (a) illustrates the dimensions of the scaled buoy.

\subsection{Modelling of the mooring system}

Mooring system software such as Orcaflex ${ }^{\mathrm{TM}}$ requires the specification of hydrodynamic parameters. Hydrostar ${ }^{\mathrm{TM}}$, a radiation/diffraction potential code, was used to calculate the hydrodynamic properties for a simplified hull shape (Fig. 1 
(d)) and for each wave frequency, from 0.11 to $13.42 \mathrm{rad} / \mathrm{s}$, in increments of $0.11 \mathrm{rad} / \mathrm{s}$. The mesh was calculated with Matlab, includes 3145 points and 3024 faces, and is symmetrical with respect to the vertical axis. This simplified shape does not include the vertical triangular braces at the bottom of the buoy (Fig. 1 (a)), therefore the added mass and hydrodynamic damping associated with these features are not accounted for. The frequency-dependent data calculated using this mesh for each of the 6 degrees of freedom of the buoy were:

a) the load Response Amplitude Operators (RAOs) and associated phases at the metacentre at the equilibrium position of the buoy,

b) the added masses at the centre of gravity (COG) of the buoy,

c) the radiation damping values at the COG of the buoy, and

d) the Quadratic Transfer Functions (QTFs) at the metacentre at the equilibrium of the buoy.

The viscous damping cannot be calculated by radiation/diffraction potential codes.

To simplify the Orcaflex ${ }^{\mathrm{TM}}$ calculations, Newman's approximation was used for the QTFs. This approximation considered that the full QTFs should not influence significantly the behaviour of the device; consequently only the mean drift forces are required to estimate the second order motion of the floating structure. Hauteclocque et al. [18] discussed the differences in results using different methods to calculate the second-order low frequency loads in shallow water and found that the two key parameters for a proper estimation of the behaviour of the moored system are the water depth and the resonance period: the Newman approximation can give accurate results for a compliant system in deep water. For this experiment, the low Ursell number (eq 1) [19] indicates that the conditions are linear (linear wave theory). Furthermore, the mooring system is highly compliant, and its resonance frequencies, highlighted by the regular wave tests are relatively small.

In order to validate this assumption, a model runs with the full QTFs will be compared with a model using the Newman's approximation in subsection 3.4 .

$U r_{\max }=\frac{H_{\max } \lambda_{\max }^{2}}{8 \pi^{2} h^{3}}=\frac{0.5 \times 5.2^{2}}{8 \pi^{2} 5.95^{3}}=0.00081<<1$

where $H_{\max }$ is the highest wave height used for regular wave tests, $\lambda_{\max }$ is the highest wave length used for regular wave tests and $h$ is the water depth.

\section{Validation results}

This section will present results from the different tests. The aim of this series of tests is to obtain an accurate model in realistic sea states. As shown in Fig. 2, each test will provide different information about the hydrodynamics of the buoy and its mooring. This information will then be used to finely calibrate the numerical model and correct potential inaccuracies. The calibration of the model will be done using best fit models a) for the surge added mass, quadratic damping and linear damping using the decay test results and b) for the pitch quadratic damping and surge QTFs using the regular wave test results. The drag forces applied on the mooring lines are assumed to be correct.

The numerical model is build using the potential radiation-diffraction theory. Consequently, the buoy properties (RAOs, added mass...) have been calculated for a constant draft and for infinitesimally small waves. As discussed previously, the Newman's approximation has been used for the QTFs to simplify the calculations. 


\subsection{Static and quasi static tests}

Static tests were conducted in still water conditions to determine the buoy draft, with and without mooring lines in place. In free-floating conditions, before attaching the mooring lines, the centre of gravity of the buoy was at $0.078 \mathrm{~m}$ below the mean water level in the basin. This distance was set in the numerical model. After the attachment of the mooring lines, the centre of gravity was $0.10 \mathrm{~m}$ below the mean water level and the mooring pre-tension was $18 \mathrm{~N}$ in both the basin and the numerical model.

Quasi-static tests were used to identify the horizontal stiffness characteristics of the mooring system, by determining the relationship between the buoy horizontal position and the mooring line tensions. The model was placed in the basin in still water conditions. The buoy was held in different surge positions and the mooring tensions were measured for each surge position.

The results of the quasi-static tests are presented in Fig. 3 (a), indicating the tension in the mooring lines for a given surge offset. The results of the tank tests and of the numerical model show an excellent agreement with a relative error not exceeding $6 \%$ (Fig. 3 (b)).

\subsection{Decay tests}

Decay tests were carried out to evaluate the linear and quadratic damping and the added mass of the buoy from its natural period. Decay tests involved moving the moored buoy from its equilibrium position in one degree of freedom and then releasing it. The buoy is moving at its natural frequency for this degree of freedom, and the amplitude of motion is decreasing because of the damping of the system. A Matlab ${ }^{\text {TM }}$ code called Wave Analysis for Fatigue and Oceanography, usually referred to as WAFO [20], was used to detect peaks and troughs in the decay time series. The first decay oscillation was ignored for calculation, because the buoy may have experienced additional damping due to the release of the mooring. For each decay test, the subsequent 5 peaks and 5 troughs were used to calculate the natural period and damping coefficients. The amplitude of release used for the numerical model was the mean amplitude after the first oscillation during the tank tests. The amplitudes of release and after one oscillation during tank tests are given in Table 3 (surge) and Table 4 (pitch).

The natural period depends mainly on the stiffness of the moored system, its mass and added mass [21]. Quasi static tests indicated that the stiffness of the mooring system in the numerical model is very close to the experimental stiffness, and the model buoy was weighed before the tank tests, as shown in Table 2, with a perfect agreement between the experimental and numerical values. By elimination of the other parameters, this means that the natural period will validate the value of added mass calculated by the radiation-diffraction code. The natural period was calculated as the mean time between similar extreme values (peak or trough).

The radiation damping forces depend linearly on the magnitude of relative velocity of the sea past the buoy, and the viscous damping by a quadratic relationship. The overall damping was calculated for the tank tests and for the numerical model, and was separated into a linear and a quadratic coefficient: $p_{1}+p_{2}\left|\xi_{j}\right| i \omega$, with $\xi_{j}$ the motion amplitude in one degree of freedom and $\omega$ the angular frequency. $p_{1}$ and $p_{2}$ are coefficients which can be calculated using the relation described by Faltinsen [22], assuming the damping to be constant with respect to the oscillation amplitude:

$$
\frac{2}{T_{m}} \log \left(\frac{X_{n-1}}{X_{n+1}}\right)=p_{1}+\frac{16}{3} \frac{X_{n}}{T_{m}} p_{2}
$$

where $X_{n}$ is the amplitude of the $\mathrm{n}^{\text {th }}$ oscillation and $T_{m}$ is the natural period of oscillation. Fig. $4(\mathrm{a})$ and (b) illustrate this method: a) extremes are detected, and b) $\frac{2}{T_{m}} \log \left(\frac{X_{n-1}}{X_{n+1}}\right)$ is plotted against $\frac{16}{3} \frac{X_{n}}{T_{m}}$, allowing the calculation of $p_{1}$ and $p_{2}$ by linear regression using a least squares method. The norm of the residual was calculated to give an indication of the goodness of the fit. 
Decay results from the tank tests and from the initial numerical model are presented in Fig. 5 (a) and (b) and Table 3-5. Test repeatability was evaluated using the standard deviations of natural period, damping coefficients and norms of the residuals between the different experiments. Table 3 indicates that for the different surge decay tests, similar results were obtained for the natural period and the quadratic damping coefficients, and more variability was observed for the linear damping coefficients. Because of this repeatability, the values chosen to calibrate the numerical model are the mean values of natural period and damping coefficients over the six experiments. The pitch decay tests provide a larger range of natural period and damping values for the different experiments. This lack of repeatability may be due to a coupling of the pitch motion with the surge motion, as seen in Fig. 5 (b). In these cases, large amplitudes of the surge motion-up to $0.4 \mathrm{~m}$ are observed and the pitch motion does not oscillate around zero. Because of this lack of repeatability, the pitch motion properties could not be evaluated accurately and the experimental values could not be used to calibrate the numerical model.

The initial numerical model was underestimating the damping of the system and the natural period in surge (Fig. 5 (a), Table 5). The inaccuracies in the added mass and linear damping may have been due to the simplified shape or the inabilities of the radiation-diffraction model to evaluate viscous damping. Following an iterative process, the added mass, linear and quadratic damping values were adjusted until the numerical natural periods and damping coefficients matched the experimental values:

a) The surge added mass is multiplied by coefficients between 1 and 1.5 for all the wave frequencies and simulations are run with these corrected added masses; the natural period is calculated for each added mass simulation and plotted against the multiplying coefficients (Fig. 6 (a)). A linear fit estimates the value of the multiplying coefficient which leads to a similar experimental and modelled natural period.

b) Additional quadratic damping value is added to the numerical model with values between 0 and the total quadratic damping value, $p_{2}$, calculated from the tank tests. Simulations are run with this additional damping. The quadratic damping coefficient, $p_{2}$, is calculated for each simulation and plotted against the additional quadratic damping (Fig. 6 (b)). A linear fit gives the value of additional damping which leads to a similar experimental and modelled quadratic damping, $p_{2}$.

c) Additional linear damping is slowly increased in the numerical model. For each value of additional linear damping, the linear damping coefficient, $p_{1}$, is calculated and plotted against the value of additional linear damping (Fig. 6 (c)). Following a similar method than previously, a value of additional linear damping is chosen for further calculations.

Calibrations are summarised in Table 6 . For the surge, the corrected model shows a good agreement with the experimental data, as seen in Fig. 5 (a) or Table 5, with less than $8 \%$ relative error between the measured and modelled natural periods and damping values.

\subsection{Regular waves tests}

Regular wave tests aim to evaluate Response Amplitude Operators (RAOs) of the buoy motions together with the mean drift for a large range of wave periods and wave steepness values. The RAOs are transfer functions indicating the response of the buoy in each degree of freedom for a range of wave frequencies. The damping of the pitch motion will also be assessed.

A total of 36 different tests were carried out using sinusoidal waves with wave periods and wave heights from $0.88 \mathrm{~s}$ to 2.3 $\mathrm{s}$ and from $0.03 \mathrm{~m}$ to $0.5 \mathrm{~m}$ respectively as shown in Fig. 7 (a). These tests correspond to waves with a period from $1.97 \mathrm{~s}$ to $5.14 \mathrm{~s}$ and a height from $1.5 \mathrm{~m}$ to $2.5 \mathrm{~m}$ at full scale, which are operational sea states at the SWMTF site, but not extreme sea states. The choice of wave period and wave frequency was limited by the wave-breaking limit $(H / \lambda=0.14$ in deep water with $H$ is the wave height and $\lambda$ is the wave length) as well as the performance of the tank. Steep waves were defined as (Fig. 7 (b), [23]:

$K_{C}>\frac{1}{2} \frac{0.14 \pi \lambda}{D}$

where $K_{C}$ is the Keulegan-Carpenter number, and $D$ is the buoy diameter $(\mathrm{m})$.

Steep waves (filled circles in Fig. 7 (a)) were used to observe non-linear behaviour, while waves with small amplitudes were used to determine the validity of response predictions based on linear wave theory. Wave periods near the resonance 
periods of the system were investigated in detail. The tests were run for at least 10 wave periods in order to observe the steady response of the floating structure.

Time series of experimental and modelled wave elevations and buoy motions are analysed using a least squares fit method to estimate the amplitude, period and phase. In effect the time-series are fitted to a cosine as described in equation (4) and shown in Fig. 8 (a). The mean of the motion, which is also the mean drift, was removed before the fit. The covariance is used as a correlation coefficient and was calculated between the original data and the fitted curves.

$$
\begin{aligned}
& \operatorname{Wavefit}(t)=\frac{H_{w}}{2} \cos \left(\omega_{w} t+\varphi_{w}\right) \\
& \operatorname{Motionfit}(t)=\frac{H_{m}}{2} \cos \left(\omega_{w} t+\varphi_{m}\right)
\end{aligned}
$$

For the initial numerical model, very good agreement was achieved for the heave, pitch and the waves, with values over 99\% for the correlation coefficient between the data and the fit for the numerical and experimental heave, and over $83 \%$ for the pitch. The only fit which has a significantly lower correlation coefficient was for the experimental surge motion, with correlation values down to $42 \%$ for combinations of low wave periods and wave heights as shown in Fig. 8 (b). In these cases, a low frequency surge motion was observed in the tank (Fig. 8 (c)), and the mean drift presents some inaccuracies. This low frequency motion may have been due to wave reflection on the walls of the basin. The solution to validate the fit was to filter the surge motion with a moving average using 250 data points, which removes the slow motion of the buoy. The filtered data and the fit show correlation coefficients over $97 \%$, which validates the fit.

The RAOs were then calculated as $H_{m} / H_{w}$ and the associated phases as $\varphi_{m}-\varphi_{w}$. The mean drift was divided by the square of the wave amplitude because the drift forces are proportional to the wave amplitude squared.

Results for the regular waves are presented in Fig. 9 (mean drift) and Fig. 10 (motion RAOs and phases). Red circle markers indicate values measured during the experiment and black diamond markers values calculated by the initial numerical model. Filled markers are used for data obtained with steep waves, as defined previously.

Results indicate that for wave frequencies over $0.9 \mathrm{~Hz}$, the modelled mean drift (Fig. 9) was underestimated by the initial numerical model and actually appeared to decrease between 0.9 and $1 \mathrm{~Hz}$ for the initial numerical model, with a minimum value at $19 \mathrm{~m} / \mathrm{m}^{2}$ at $1 \mathrm{~Hz}$ while the minimum experimental value is at $40 \mathrm{~m} / \mathrm{m}^{2}$. This inaccuracy originates from the potential radiation-diffraction code which calculated the mean drift forces with this shape before inputting them into the numerical model. A methodology to correct the QTFs will be proposed below.

The main result from the RAO analysis is that the initial modelled pitch RAOs are largely overestimating the pitch RAOs around the resonant frequency $f=0.9 \mathrm{~Hz}$. The maximum modelled value at this frequency was equal to $843^{\circ} / \mathrm{m}\left(8.43^{\circ} / \mathrm{cm}\right)$ while the maximum experimental value was equal to $521^{\circ} / \mathrm{m}(5.21 \% \mathrm{~cm})$. These values seem at first unrealistic because too high but results were obtained for very small wave heights and are presented at the model scale. For example, for the highest experimental value, $H$ was equal to $0.03 \mathrm{~m}(3 \mathrm{~cm})$ and $T$ was equal to $1.08 \mathrm{~s}$ meaning that the buoy was pitching with an amplitude peak to peak of $521^{\circ} / \mathrm{m} \times 0.03 \mathrm{~m}=15.6^{\circ}$ (Fig. 11). These results confirm the highly dynamic behaviour of the mooring system.

The high values in the initial numerical model are due to the lack of damping in pitch, with quadratic damping forces not considered in the numerical model at this stage as described in the previous section. A methodology to add quadratic damping will be proposed below. 


\section{Calibration of the mean drift forces in the surge direction}

The mean drift values in surge were corrected by calibrating the mean wave drift force values in the surge direction (Fig. 12):

a) The mean drift forces are multiplied by different coefficients between 0.5 and 10 . Each regular tank test is replicated in the numerical model for the different input values of mean drift forces and mean drift is calculated for each test.

b) For each test over $0.85 \mathrm{~Hz}$, the difference between the mean drift for the experiment and for the numerical model is plotted against the different multiplying coefficients. A linear fit is applied to select the value which equates the difference to zero.

c) The values to equate the difference to zero in each test are plotted against the wave frequency. A smoothing spline is fitted to these values, and interpolated multiplying coefficients are output.

d) The initial mean drift force is multiplied by the interpolated multiplying coefficients, and to avoid a large step in the data, data are linearly interpolated.

However, for wave frequencies outside of the range used in this study, the validity of the modelling of the mean drift is not known. For low frequencies, the difference of mean drift between the numerical model and the experiment tends towards zero, but for high frequencies, further investigations are required to validate the modelling of the mean drift. Once the numerical model has been corrected the experiment (red circles) and the model (blue squares) were giving similar results in the considered range of steep and linear waves (Fig. 9).

\section{Calibration of the quadratic pitch damping}

Quadratic pitch damping was added using a sensitivity analysis (Fig. 13):

a) Several values of quadratic damping are considered between 0 and $0.0035(\mathrm{kN} \cdot \mathrm{m}) /(\mathrm{rad} / \mathrm{s})^{2}$, numerical models are run with these different values for all regular sea states and pitch RAOs are calculated.

b) The sum over the different sea states of the absolute value of the difference between the numerical and the experimental pitch RAO is calculated for each considered quadratic damping values. The sea states are separated between linear waves and steep waves. The relationship between the sum and the quadratic damping is highlighted by a second order polynomial fit line, and the minimum of this line is calculated, giving the optimum quadratic damping value.

This method assumes that the pitch linear damping value in the numerical model is correct. The RAOs for the corrected numerical model are plotted in Fig. 10 with blue squares. The addition of quadratic pitch damping also leads to a better fit of the modelled surge RAOs and improves the modelled heave RAOs near the pitch resonance.

After correction, the modelled mean drift (Fig. 9) and RAOs amplitudes and phases (Fig. 10) are in good agreement with the experimental values. The amplitudes and phases of the corrected modelled RAOs indicate no significant difference in prediction for linear or steep waves.

\subsection{Irregular wave tests}

Irregular wave tests were used to validate the numerical model for realistic sea states. The wave elevation input signals for the tank were scaled time series of water surface elevation recorded during sea tests at the SWMTF. The inputs used for the numerical models were waves measured at $100 \mathrm{~Hz}$ during the tank tests. The spikes were removed in the time domain: if the absolute difference between two adjacent points was higher than 5 times the standard deviation of the signal or 3 times the absolute differences on the two preceding adjacent points, the last point was removed; (Fig. 14 (a)). Finally the corrected signal was re-sampled at $4 \mathrm{~Hz}$ to simplify Orcaflex $^{\mathrm{TM}}$ calculations (Fig. 14 (c)). Three different sea states (Table 7) were chosen, with a duration of approximately $500 \mathrm{~s}$ each (model scale). The correlation coefficients between the 
experiment, the numerical model and the standard deviations for surge, heave and pitch motions as well as mooring loads were calculated for durations of $350 \mathrm{~s}$, in order to leave some initial time to let the model settle into its drifted position.

The choice of the sea states for tank test has been based on several considerations: a) sea states with this combination of $H_{S}$ and $T_{P}$ frequently occurs at the South West Mooring Test Facility; Case 1 and 3 were chosen with similar significant wave heights, which are close to the maximum capability of the basin, and with different wave periods. Case 2 was chosen because its wave period is close to the resonance in pitch. b) the water depth is similar for all 3 sea states, around $30 \mathrm{~m}$ at the full scale facility; $c$ ) the wave direction is similar for all 3 sea states and with the waves coming from the East at the full scale facility $\left(105^{\circ}\right.$ clockwise from the North, when line 3 was at $65^{\circ}$ and line 1 and $\left.185^{\circ}\right)$.

Data were chosen during the 2 first months of operations to avoid discrepancies due to operation (e.g. loadcell failure). More sea states would be required to draw general conclusions, these sea states are just intended to show an example of the capability of the numerical model.

An example of wave elevation time-series, positions and mooring loads recorded during the experiment and input or computed by the numerical model is given in Fig. 14 (c), Fig. 15 and Fig. 16 respectively. The correlation, evaluated with the covariance, between the measured and the input wave signal was over 0.99 for the three tests (Table 8). The heave and pitch motions are accurately replicated by the numerical model (Fig. 15 (b) and (c)). Correlation coefficients larger than 0.96 for the heave motion and 0.82 for the pitch motion support this finding, although the numerical model slightly underdamps the pitch motion. For example in case 2 (Table 7), the standard deviation of the experimental pitch motion was $5.1^{\circ}$ when the standard deviation of the modelled motion was $5.4^{\circ}$. This may be due to the fact that quadratic damping only was added to the system and linear damping could not be checked. Some differences can be observed in the surge motion, due to differences in the drift motion. In the example given in Fig. 15 (a), the buoy is reaching nearly the same minimum surge position; $-0.063 \mathrm{~m}$ for the experiment and $-0.046 \mathrm{~m}$ for the numerical model. Larger differences can be observed; for example, at $t=132 \mathrm{~s}$, the surge position is equal to $0.044 \mathrm{~m}$ in the experiment and $0.082 \mathrm{~m}$ in the numerical model. Despite these inaccuracies, the correlation coefficients are always larger than 0.77 for the surge motion.

Mooring loads are compared between the tank tests and the numerical model in Fig. 16 and Table 8. These indicate that loads are replicated with a correlation coefficient over 0.75 . Loads are slightly underestimated by the model, as shown by the standard deviations. For example, for case 2, the standard deviation in Line 1 was $1.7 \mathrm{~N}$ for the experiment when it was $1.3 \mathrm{~N}$ for the numerical model. This may be due to the underestimation of the surge motion. Maximum mooring loads are compared in Table 9. For example, the maximum mooring load on line 1 for case 2 was $27.4 \mathrm{~N}$ for the experiment and 25.9 $\mathrm{N}$ for the numerical model. These results indicate that the numerical model, in this setup, tends to underestimate the mooring loads, by $17 \%$ in the worst case.

The influence of the re-sampling of the wave input has been assessed in Table 10. A higher sampling frequency mainly has an influence on the surge motion, with a higher correlation coefficient between the modelled motion and the experimental motion when the signal is not re-sampled $(100 \mathrm{~Hz}$, correlation coefficient up to 0.8218$)$ than with a sampling frequency of 4 $\mathrm{Hz}(0.8041)$.

One of the assumptions made for the numerical model was to use the Newman's approximation to simplify the QTF calculations. Table 11 compares the results for the numerical model for Case 1 using the Newman's approximation and the full QTFs with and without corrected surge mean drift forces, and the results from the experiment. Additionally Fig. 17 shows an example of the time series of motions and loads from a) the initial model with the uncorrected full QTFs, b) the final model with the Newman's approximation after correction, and c) the experiment.

Correlation coefficients between the numerical models without the diagonal corrections and the experiment are calculated for the motions and mooring loads. These coefficients are lower when the full QTF are used, especially for the surge $(0.73$ with the full QTF and 0.81 with the Newman's approximation) and pitch motion ( 0.76 with the full QTF and 0.91 with the Newman's approximation).

The mean surge motion is improved by the use of the corrected mean drift values, for both models using the Newman's approximation or the full QTFs, by reducing the relative error from $23 \%$ to $8-9 \%$. The maximum loads and standard deviations of the loads are generally slightly better estimated by the numerical model using the full QTFs, with or without diagonal correction.

To summarise, the use of the full QTFs instead of the use of the Newman's approximation does not significantly improve the results (estimation of the mean, max and standard deviations of the motions and loads). 
The motions and loads obtained with the tank tests are compared with the results in the field at the SWMTF (Fig. 18, Table 12). Results are presented at the model scale. It should be noted that the wave elevation used as an input in the tank test at the position $(0,0,0)$ was the elevation measured by a beam of the acoustic Doppler current profiler (ADCP), several meters away from the buoy. Consequently, the phases of the loads and motions are different. Also the wave direction was slightly different: in the tank, waves were coming exactly between the 2 front mooring lines. In the field, waves were coming $20^{\circ}$ from the middle of the front lines, closer to line 3 .

Fig. 18 (a-c) and Table 12 indicate that the mooring load mean, maximum and standard deviation are usually higher in the field, up to $70 \%$ higher for the mean load and $82 \%$ for the standard deviation of the load. Fig. 18 (d) and Table 12 also show that in the field, there is an offset in the mean buoy position. Fig. 18 (d-e) and Table 12 indicate that the variations in the mean buoy position are higher for the tank tests, with a standard deviation of the surge motion $57 \%$ to $120 \%$ higher for the tank tests than for the field tests. One of the main reasons which could explain the differences in mooring loads and buoy position is the inaccurate positioning of an anchor, as explained by Harnois et al. [9]. Also the mean load is higher in line 3 in the field tests because the measurements for this loadcell drifted. The mean loads on line 1 and 2 are underestimated by 4 to $45 \%$ by the tank experiments.

For this study, scaling effects are minimised by using a relatively large scale, and ensuring that the Reynolds number is similar for the model scale, and for the full scale device. However, it was not possible to find a rope with an exact 1:5 Froude scale stiffness. A sensitivity analysis has been run with the numerical model in order to assess the influence of mooring stiffness on the mooring behaviour. The numerical model has been run with the irregular waves used in Case 2 (Table 7) using different rope stiffness, up to 10 times smaller or 100 times higher than the stiffness used in the final model $(10.873 \mathrm{kN})$, named below the reference stiffness. The correlation coefficients between the time-series of motion and loads of the models with a given stiffness and with the reference stiffness were calculated. Results were normalised by dividing them by the reference stiffness results and are presented in Fig. 19 (a). The correlation coefficients between the reference and the modified models for the mooring loads dropped down to 0.85 when the stiffness is divided by 10 , but no significant changes are observed in terms of motions and loads otherwise. Similarly, for each model with a given stiffness, the maximum load was evaluated and normalised by the maximum load for the reference stiffness and results are presented in Fig.19 (b). The maximum modelled mooring loads dropped down in line 1 for the most compliant rope.

\section{Discussion}

The paper has presented a range of experimental investigations that validated the numerical model. These investigations give insight into specific and more general considerations: difference between the SWMTF and a real wave energy device, validation of the numerical model for a wide range of sea states, limitation of the radiation/diffraction potential analysis, possible improvements to the numerical model, scaling limitation especially for the stiffness of the mooring rope, and combination of numerical model and tank test to gain more insight into the behaviour of a mooring system in real sea conditions.

The aim of this numerical model was to gain a better understanding of dynamics of mooring system of wave energy devices in real conditions, using the SWMTF as a case study. The highly dynamic behaviour of the mooring system used at SWMTF is typical of the mooring system of a motion-dependent wave energy device such as a point absorber. The methodology used in this paper can be used for similar wave energy mooring tank tests. However, in comparison with an operating wave energy device, the SWMTF does not have a power take-off, which will provide additional damping and reduce the amplitude and velocity of the motion of the buoy.

It should also be noted that the presented tank tests were not conducted to estimate the behaviour in extreme conditions, i.e. to explore the survivability of the device, but to analyse the operational behaviour characteristics. At the SWMTF, 1year return period sea state has an estimated significant wave height $H_{s}$ of $3.5 \mathrm{~m}$ and peak period $T_{P}$ of $7 \mathrm{~s}$ [11]. At the 1:5 scale used in this model, this corresponds to $H_{S}$ equal to $0.7 \mathrm{~m}$ and $T_{P}$ to $3.1 \mathrm{~s}$. Hydrodynamics parameters have been 
calculated for this range of sea states. Whilst the tank tests did not cover this range of frequency they investigated the behaviour of the buoy in steep waves. For low wave frequencies, the RAOs (Fig. 10) and mean drift curves (Fig. 9) converge to a constant value, with the floating structure expected to follow the waves. The results can then be extrapolated with some confidence.

The results in irregular waves give confidence in the ability of the numerical model to predict mooring loads in real sea conditions. However, additional irregular wave tests, covering a more varied range of wave conditions, would provide greater confidence in the results. For the available results, the inaccuracies have been quantified. In particular, the maximum mooring loads are underestimated by 5 to $17 \%$ (Table 9 ) which is acceptable because typically a safety factor of $1.4[14]$ is applied.

The main discrepancy which has been observed in the numerical model regards the mean drift, which is not accurately modelled especially for the highest wave frequencies, at the pitch resonance. It is however accurately modelled for the short wave frequencies which are of interest because associated with storms. This was also the case with a similar buoy during experiments performed by Cozjin et al. [24]. Cozjin et al. suggested that inaccuracies in the surge wave drift forces may be linked to inaccuracies in the first order vessel motions. In Cozjin et al and in this paper, the first order pitch motion was overestimated by the numerical model, because it was lacking of viscous damping. This may have induced the inaccuracies for the surge wave drift motions. The lack of viscous damping was due to the limitations of the radiation/diffraction potential analysis which does not include viscous effects.

Cozjin et al. also noticed that the heave and pitch added mass were underestimated by a linear radiation-diffraction potential code for a similar buoy. In this paper, it was found that the surge added mass was underestimated by the linear radiation-diffraction code. Cozjin suggested that it was due to the fact that rotational accelerations in the fluid are not taken into account by this kind of code.

CFD could be the solution for the lack of viscous damping and the absence of rotational accelerations in the fluid. Bunnik et al. [25] suggested using Computational Fluid Dynamics (CFD) in the future to predict viscous forces. Palm et al [26] and Yu and Li [27] started investigating CFD for wave energy devices.

Furthermore, radiation/diffraction potential usually used a simplified shape of the hull to reduce the computation time, but this could introduce inaccuracies for added mass and radiation parameters..

Numerical results could be slightly improved by using a higher time resolution for the wave input into the numerical model. However, these corrections are time consuming and would make the numerical model tedious to use for further investigations.

In this paper, a method has been developed to adjust added mass, radiation and quadratic damping values based on natural period, linear and quadratic damping decay results respectively. However, this method was not applicable for the pitch decay tests, because the pitch motion was coupled with the surge motion and the relative contribution of pitch radiation and quadratic damping could not be determined experimentally. Because of this, the pitch radiation damping was assumed to be correct, and the pitch quadratic damping was corrected using the pitch RAO plot from the regular wave tests. Forced oscillation tests would have isolated the pitch motion.

The results of the sensitivity analysis in irregular waves for different rope stiffness indicate that in this particular case, with a model stiffness of $10.873 \mathrm{kN}$ when the equivalent scaled stiffness of the full scale facility was between 7.1 and $7.8 \mathrm{kN}$, the motions and mooring loads were not biased by the difference of stiffness of the rope. These results also more generally indicate that for tank tests, when no accurate information is available on the stiffness of the mooring ropes (full scale or model scale), or when the choice of model mooring rope is limited, it is better to choose a stiffer rope than what is desired, and that this will not have a significant consequence on the tank test results.

Tank tests do not take into account some changes which occur in real sea conditions. For this particular case, the incorrect position of an anchor in the field significantly modified the mooring loads and the buoy mean position. This problem is likely to occur for other wave energy devices unless specific anchors are developed. At SWMTF, drag embedment anchors were used because of their efficiency and cost-effectiveness. However, the method to install this kind of anchor does not allow an accurate positioning, and the consequences of an inaccurate positioning are higher in a shallow water depth which is typical to a wave energy site. 
Another change which is not taken into account by the tank tests is the variations in water depth; these variations lead to change in pre-tension and consequently change in the behaviour of the mooring system. The tidal range to nominal water depth ratio is $20 \%$ at the SWMTF, and approximately $10 \%$ at full scale facilities (WaveHub and EMEC [10]).

Hence tank tests and numerical models are complementary. Tank tests determine the hydrodynamic behaviour of the floating structure and mooring; numerical models allow the variation of those parameters that were fixed or not explored in the tank.

\section{Conclusions and further work}

This paper describes the detailed validation of a numerical model of a wave energy mooring system using tank test results. The mooring system used for this study was a 1:5 scale model catenary mooring system made of chains and representations of nylon mooring ropes. Static and quasi-static tests were used to check the buoy draft and the tension characteristics of the mooring system. The decay tests were used to estimate the overall damping and the added mass of the system. Regular wave tests were used to obtain the buoy motion RAOs, their phases and the buoy mean drift. The irregular wave tests have been performed to replicate real sea conditions at model scale, and to compare experimental with modelled results for motions and mooring loads. Results for irregular wave tests validate the numerical model for representative operational sea conditions. Despite some inaccuracies, which have been quantified, such a model validation gives much needed confidence in the ability of the numerical model to predict mooring loads at an early design stage.

The numerical model presented here will be used for further research into mooring systems, for example to improve the understanding of extreme mooring loads. This understanding is fundamental for the design of a mooring system. In particular, further tank tests have been conducted using different materials in order to simulate marine growth and assess the different parameters associated with it: change of mooring stiffness, addition of mooring mass, increase in mooring line diameter and drag coefficient. This model can also be used to improve the understanding of the hydrodynamics of the full scale SWMTF mooring system. Simulating real wave conditions will allow a better understanding of the mechanisms involved in extreme mooring loads, for example wave grouping or acceleration in buoy movements, and consequently an improvement of the mooring design. However, several barriers have been highlighted; for example; the anchor position [9] was not accurate at the full scale facility, leading to a different pre-tension at the facility than the design one. At the moment, the model can be used as a reference before conducting any engineering changes at the full scale facility, for example changing the rope materials to investigate fibre rope behaviour in long-term real sea conditions.

The methodology presented in this paper can be used by wave energy developers in the development of cost effective mooring systems which will contribute to the efficiency of wave energy devices. Tank tests are at the moment essential to improve the modelling of new designs of mooring systems; however they are expensive and time-consuming. Numerical models contribute to improve the understanding of the mooring behaviour, to reduce the unknowns and consequently build a cost-effective mooring system, specifically designed for a given wave energy device and installation site. However, inaccuracies occurring during field tests need to be considered.

\section{Acknowledgments}

The authors acknowledge the support of the MERiFIC project partners (Marine Energy in Far Peripheral and Island Communities, http://www.merific.eu) and of MARINET, a European Community Research Infrastructure Action under the FP7 Capacities Specific Programme (www.fp7-marinet.eu).

The authors would like to acknowledge the support of the South West Regional Development Agency for its support through the PRIMaRE institution and the support towards the FabTest through the Regional Growth Fund.

The authors are grateful for the valuable support of the Ifremer team: Emmanuel Mansuy, Aurélien Tancray, Christophe Maisondieu and Peter Davies.

The authors also want to thank Orcina for their technical support. 


\section{References}

[1] Bedard R, Hagerman G, Previsic M, Siddiqui O, Thresher R, Ram B. Offshore wave power feasibility demonstration project, EPRI; 2005

[2] Carbon Trust and Black \& Veatch. Accelerating marine energy. The potential for cost reduction - insights from the Carbon Trust Marine Energy Accelerator; 2001

[3] Harris RE, Johanning L, Wolfram J. Mooring systems for wave energy converters: a review of design issues and choices. In: Proceedings of the International Conference on Marine Renewable Energy (MAREC), Blyth, UK; 2004

[4] Forestier JM, Holmes B, Barrett S, Lewis AW. Value and Validation of Small Scale Physical Model Tests of Floating Wave Energy Converters, In: Proceedings of the $7^{\text {th }}$ European Wave and Tidal Energy Conference (EWTEC), Porto, Portugal; 2007

[5] Vicente PC, Falcão AFO, Justino PAP. Non-linear Slack-Mooring Modelling of a Floating Two-Body Wave Energy Converter, In: Proceedings of the $9^{\text {th }}$ European Wave and Tidal Energy Conference (EWTEC), Southampton, UK; 2011

[6] Friis-Madsen E, Sørensen HC, Parmeggiani S. The development of a 1.5 MW Wave Dragon North Sea Demonstrator, In: Proceedings of the $4^{\text {th }}$ International Conference on Ocean Energy (ICOE), Dublin, Ireland; 2012

[7] Zanuttigh B, Angelelli E, Kofoed JP. Effects of mooring systems on the performance of a wave activated body energy converter, Renewable Energy, Vol 57, pp 422-431; 2013

[8] Fitzgerald J, Bergdahl L. Including moorings in the assessment of a generic offshore wave energy converter: A frequency domain approach, Marine Structures Vol 21, pp 23-46; 2007

[9] Harnois V, Parish D, Johanning L. Physical measurement of a slow drag of a drag embedment anchor during sea trials, In: Proceedings of the $4^{\text {th }}$ International Conference on Ocean Energy (ICOE), Dublin, Ireland; 2012

[10] Harnois V, Johanning L, Thies PR, Bjerke I. The influence of environmental conditions on the extreme mooring loads for highly dynamic responding moored structures, Submitted to Ocean Engineering; 2014

[11] Johanning L, Spargo AW, Parish D. Large scale mooring test facility - A technical note, In: Proceedings of the $2^{\text {nd }}$ International Conference on Ocean Energy (ICOE), Brest, France; 2008

[12] Weller SD, Davies P., Vickers AW and Johanning L. Synthetic Rope Responses in the Context of Load History: Operational Performance. Accepted for publication in Ocean Engineering

[13] Sharqawy MH, Lienhard V JH, Zubair SM. Thermophysical properties of seawater: a review of existing correlations and data, Desalination and Water Treatment, Vol 16, pp 354-380; 2010

[14] DNV. Offshore standard DNV-OS-E301, Position mooring; 2010

[15] Orcina. OrcaFlex manual; 2013

[16] Weller SD, Davies P, Vickers AW, Johanning L. Synthetic Rope Responses in the Context of Load History: The Influence of Aging. In review

[17] Le Roux D. MSc Thesis (in French) Rapport de Projet de fin d'études. Etude d'un ancrage textile pour la bouée SWMTF destinée à l'analyse du comportement des systèmes houlomoteurs. 2012

[18] de Hauteclocque G, Rezende F, Waals O, Chen X-B. Review of Approximations to Evaluate Second-Order LowFrequency Load. In: Proceedings of the $31^{\text {st }}$ International Conference on Ocean, Offshore and Arctic Engineering (OMAE conference), Rio de Janeiro, Brazil; 2012

[19] Molin, B. Hydrodynamique des structures offshore. Technip Edition. (in French) (2002) p 415

[20] WAFO group, WAFO A Matlab Toolbox for Analysis of Random Waves and Loads - A Tutorial, Math. Stat., Center for Math. Sci., Lund Univ., Lund, Sweden; 2000 
[21] DNV. Recommended Practice DNV-RP-H103, Modelling and analysis of marine operations; 2011

[22] Faltinsen OM. Sea Loads on Ships and Offshore Structures, Cambridge University Press, Cambridge, UK; 1990

[23] Sarpkaya T, Isaacson MI. Mechanics of wave forces on offshore structures.Van Nostrand Reinhold, New York, NY (1981) p. 651

[24] Cozijn JL, Uittenbogaard R, ter Brake E. Heave, Roll and Pitch Damping of a Deepwater CALM Buoy with a Skirt. In: Proceedings of the $15^{\text {th }}$ International Offshore and Polar Engineering Conference, Seoul, South Korea; 2005

[25] Bunnik THJ, de Boer G, Cozijn JL, van der Cammen J, van Haaften E, ter Brake E. Coupled mooring analysis in large scale model tests on a Deepwater calm buoy in mild wave conditions. In: Proceedings of the $21^{\text {st }}$ international Conference on Offshore Mechanics and Arctic Engineering, Oslo, Norway; 2002

[26] Palm J, Eskilsson C, Paredes GM, BergdahI L. CFD Simulation of a Moored Floating Wave Energy Converter. In: Proceedings of the $10^{\text {th }}$ European Wave and Tidal Energy Conference (EWTEC), Aalborg, Denmark; 2013

[27] YU Y, Li Y, Preliminary results of a RANS simulation for a floating point absorber wave energy system under extreme wave conditions. In: Proceedings of the $30^{\text {th }}$ International Conference on Ocean, Offshore and Arctic Engineering (OMAE conference), Rotterdam, The Netherlands; 2011 
Fig. 1 Wave basin installation and numerical model settings: a) side view of the buoy and dimensions, b) top view of the truncated mooring and of the wave gauge layout, c) photograph of the SWMTF model in the basin, with the false floor and d) buoy hull mesh used for the radiation/diffraction potential analysis

(a)

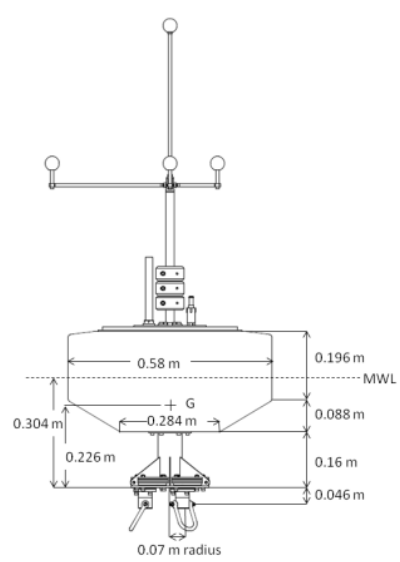

(c)

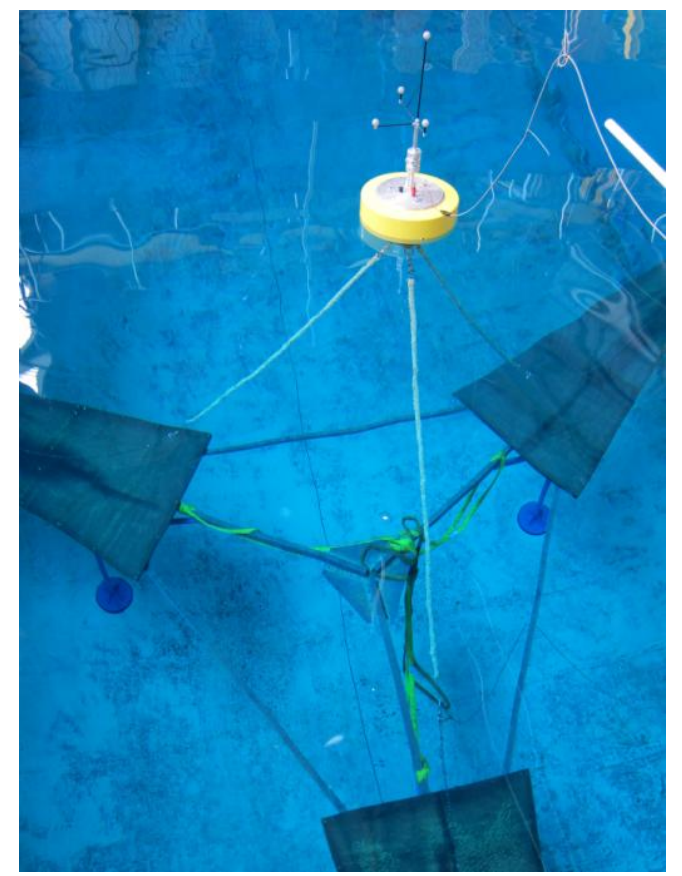

(b)

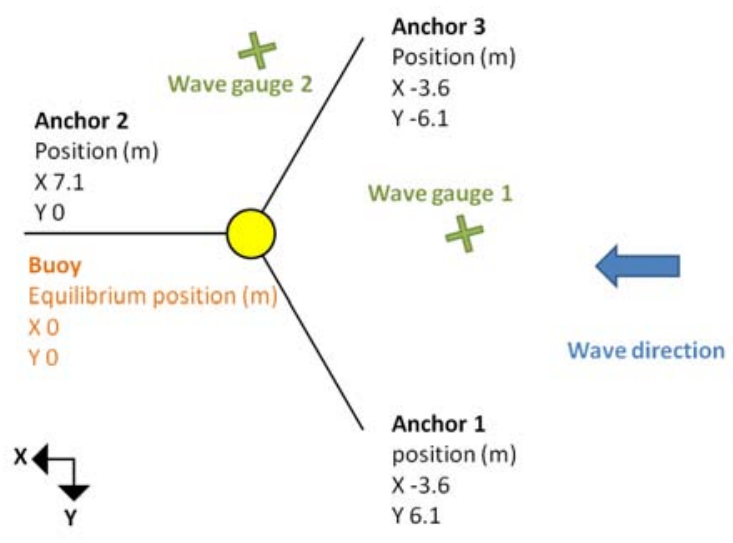

(d)

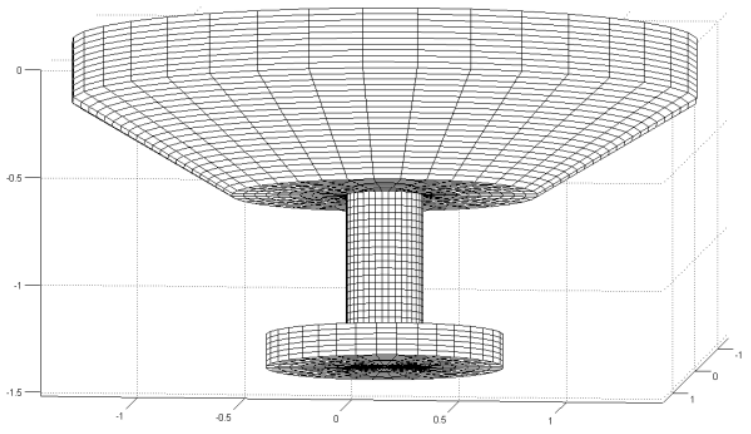


Fig. 2 Range of tests needed to validate a numerical model with experimental data

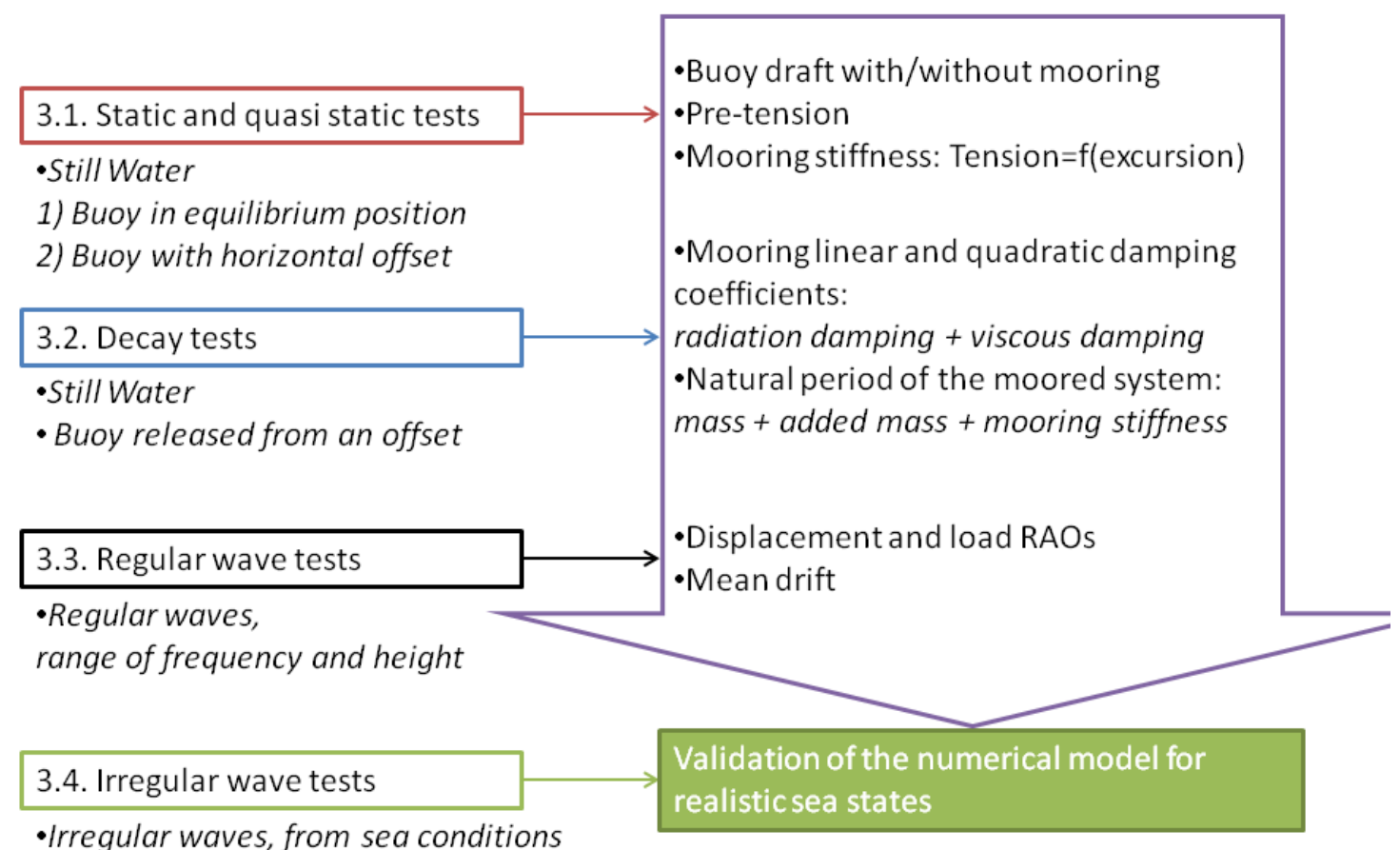

- Irregular waves, from sea conditions 
Fig. 3 Mooring stiffness: a) comparison of the experimental (red circles and solid line) and modelled (blue circles and dashed line) mooring load/buoy surge offset relationship and b) relative error in mooring tension between experimental and modelled values

(a)

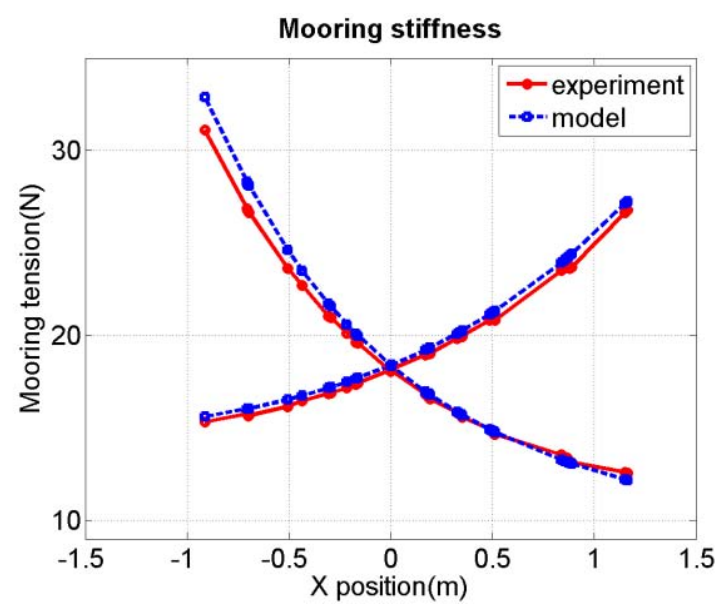

(b)

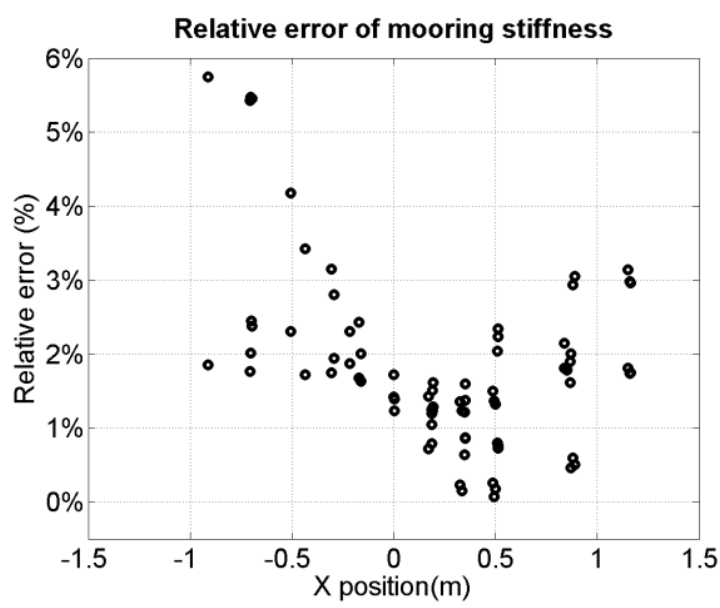


Fig. 4 Example of calculation of the natural period and linear and quadratic damping: a) detection of peaks and troughs and calculation of the natural period, b) calculation of the linear $p_{1}$ and quadratic $p_{2}$ damping coefficients using a linear fit; norm of the residua $\mathrm{I}=0.036$

(a)

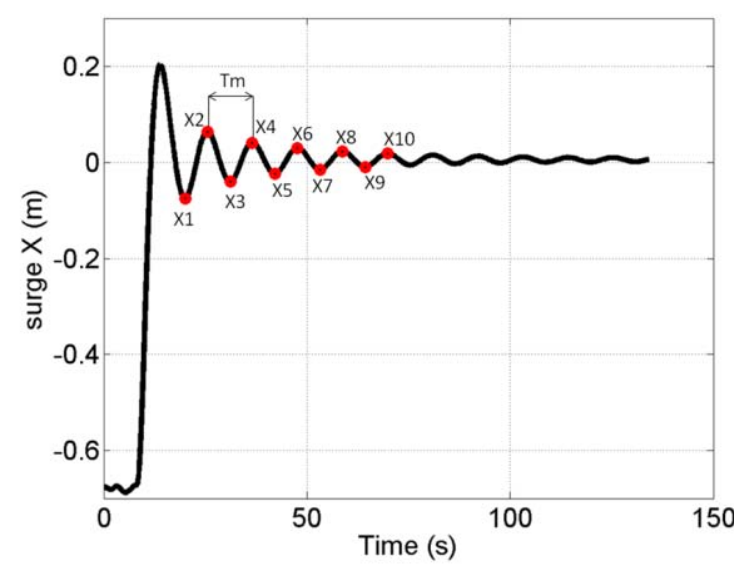

(b)

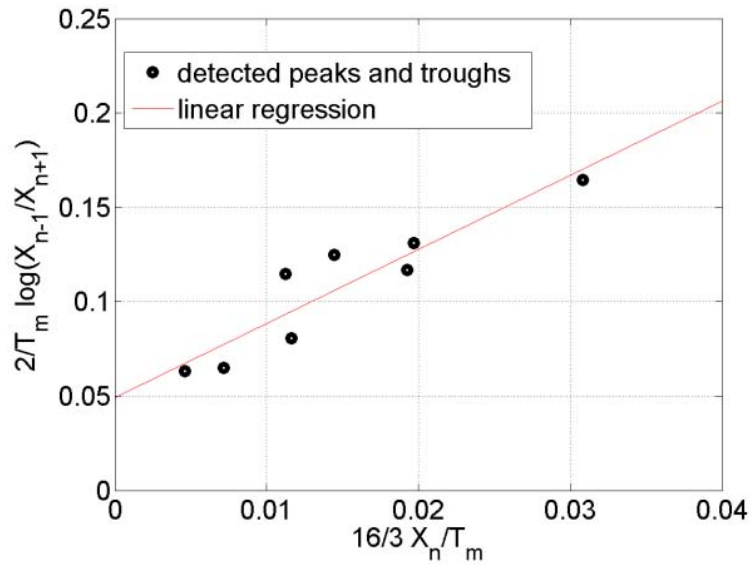


Fig. 5 Time-series of decay tests in a) surge, with comparison between the experimental values (red solid line), initial (dashed black line) and corrected numerical model (blue dotted line) and in b) pitch, with a plot of the experimental surge motion to show the coupling between surge and pitch

(a)

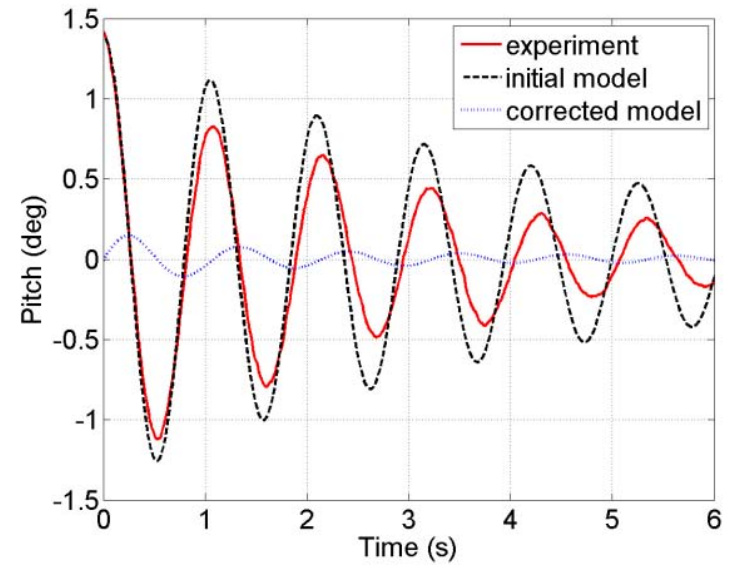

(b)
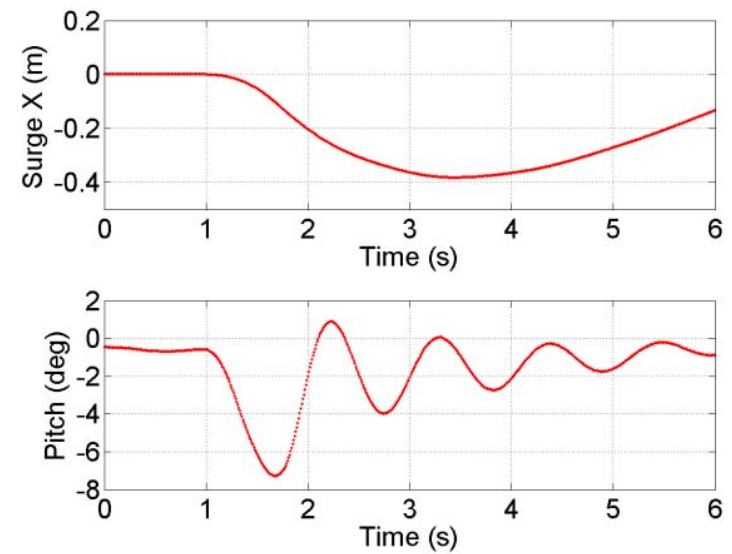
Fig. 6 Sensitivity analysis for the surge decay: a) for the added mass; b) for the quadratic damping; c) for the linear damping

(a)

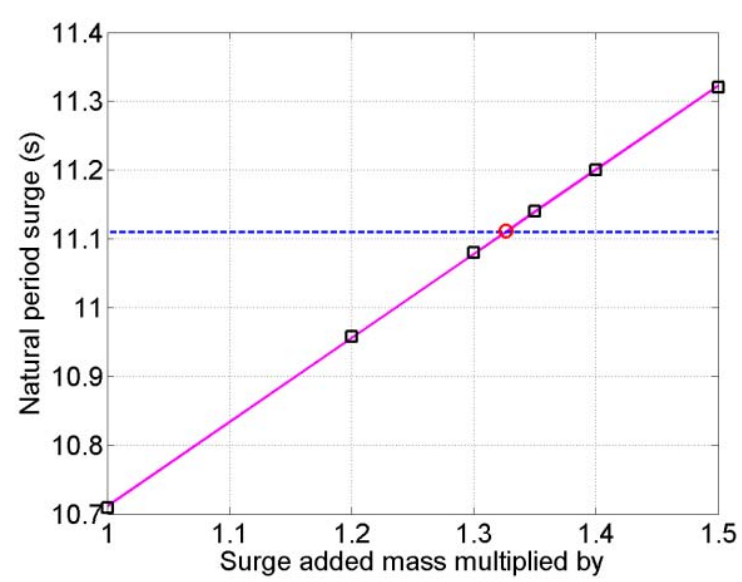

(b)

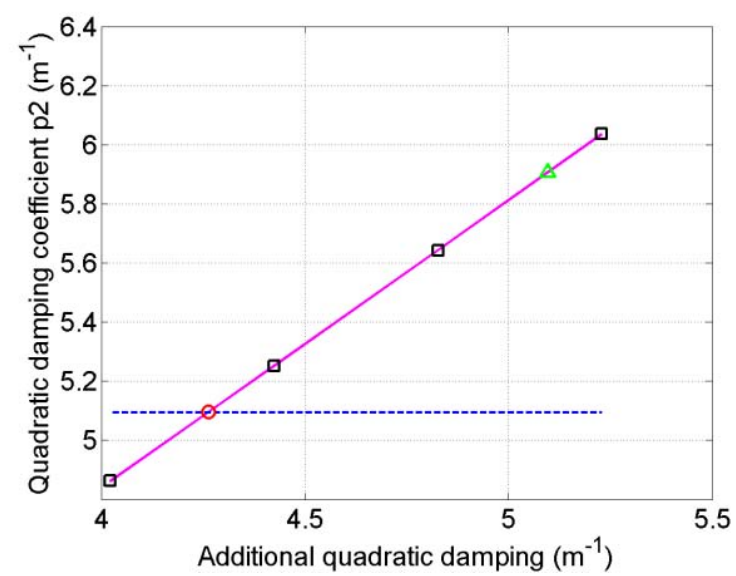

(c)

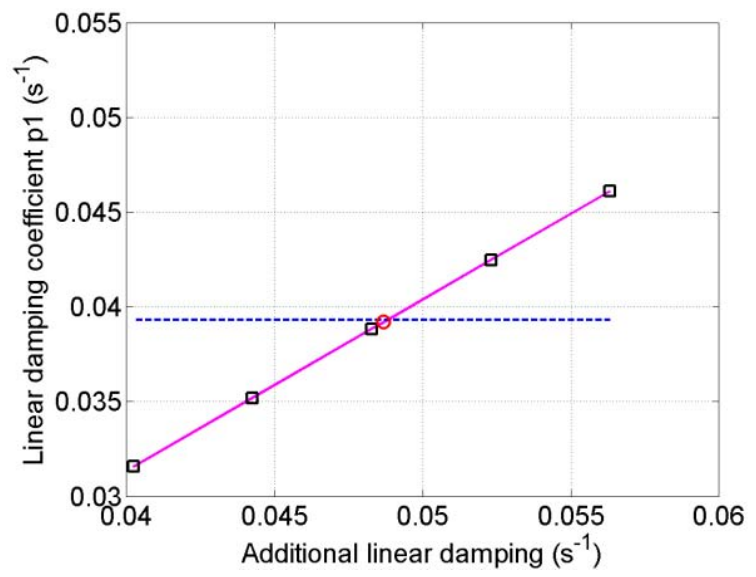

口 Sensitivity analysis

- Linear fit to the sensitivity analysis results

-- Natural period from experiment

- Chosen value after sensitivity analysis $\triangle$ Total measured quadratic damping

- Sensitivity analysis

- Linear fit to the sensitivity analysis results

---- Quadratic damping from experiment

- Chosen value after sensitivity analysis
口 Sensitivity analysis

- Linear fit to the sensitivity analysis results

---- Linear damping from experiment

- Chosen value after sensitivity analysis 
Fig. 7 Review of tests in regular waves: a) Wave heights, $H$, and wave periods, $T$, used for the tank tests. b) Selection of steep waves, the green line is for $K_{C}=\frac{1}{2} \frac{0.14 \pi \lambda}{D}$, separating the steep and the linear waves, and the blue line for $K_{C}=\frac{0.14 \pi \lambda}{D}$, separating steep waves and breaking waves. The black filled circles indicate steep waves while the red hollow circles indicate linear waves

(a)

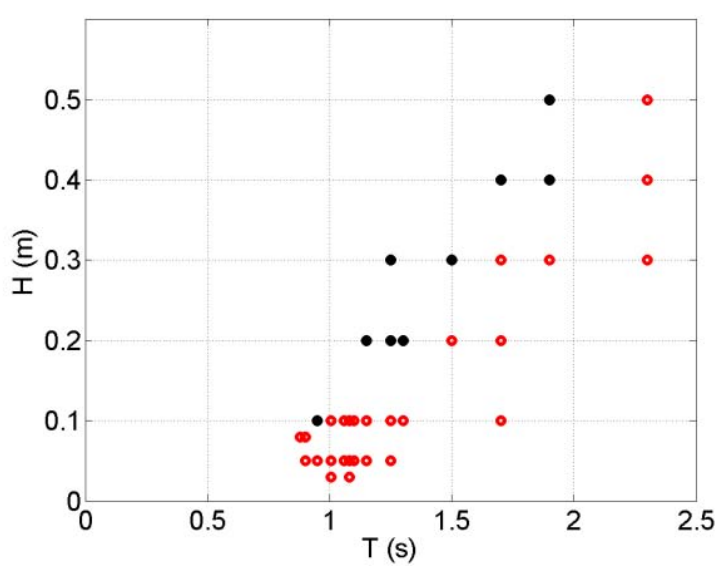

(b)

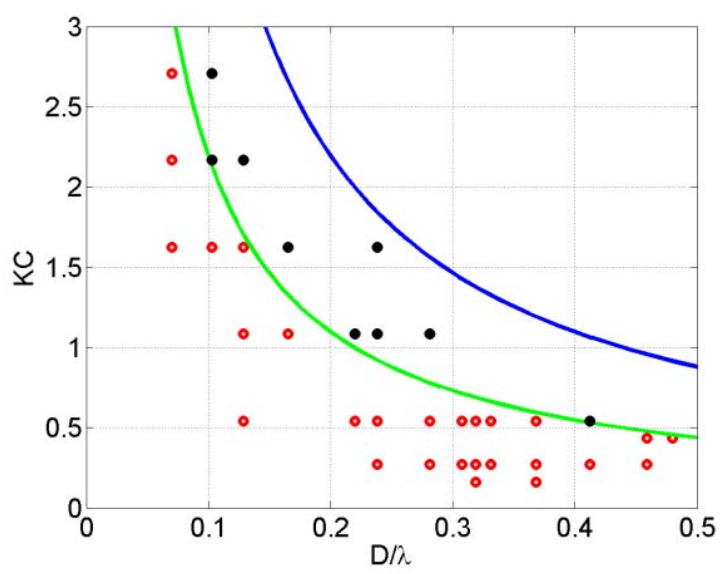


Fig. 8 Examples of fit of the experimental surge motion: a) for $H=0.1 \mathrm{~m}$ and $T=1.7 \mathrm{~s}$ (blue line: signal, black line: fit); b) Summary of the correlation coefficient between the fit and the experimental values c) Examples of fit for $H=0.05 \mathrm{~m}$ and $T$ $=0.9 \mathrm{~s}$ where $\mathrm{a}$ low frequency motion on the $\mathrm{X}$ axis can be observed (blue line: signal, black line: fit)

(a)

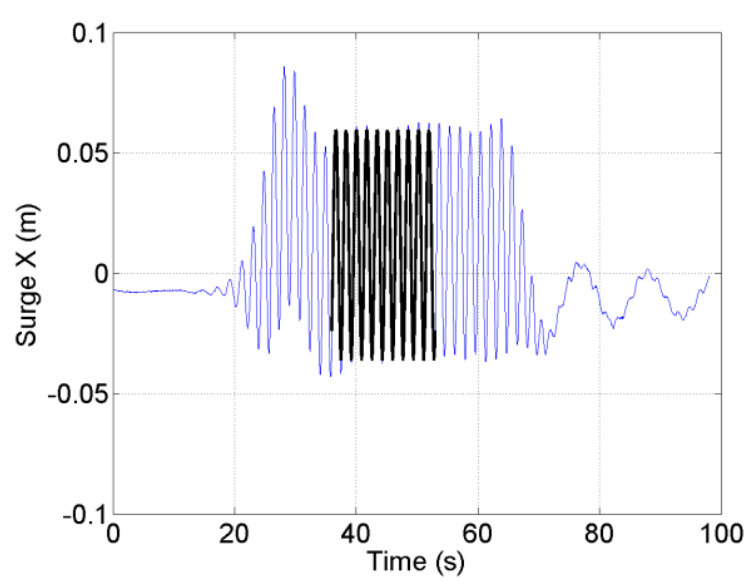

(b)

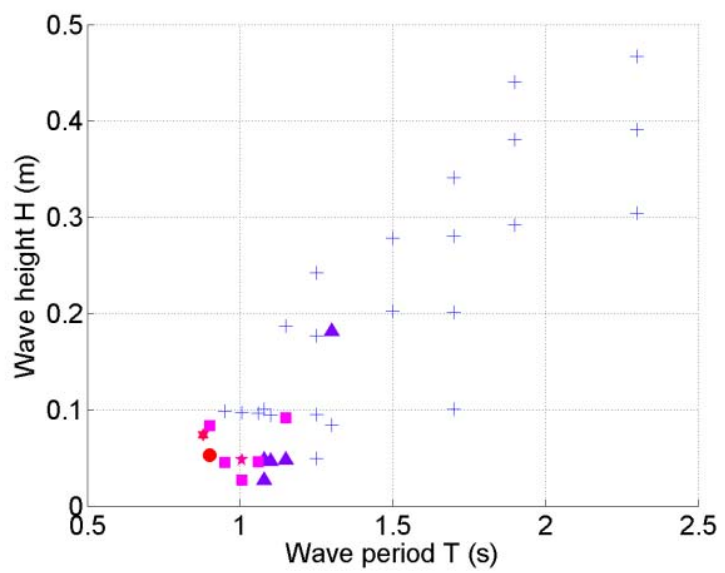

(c)

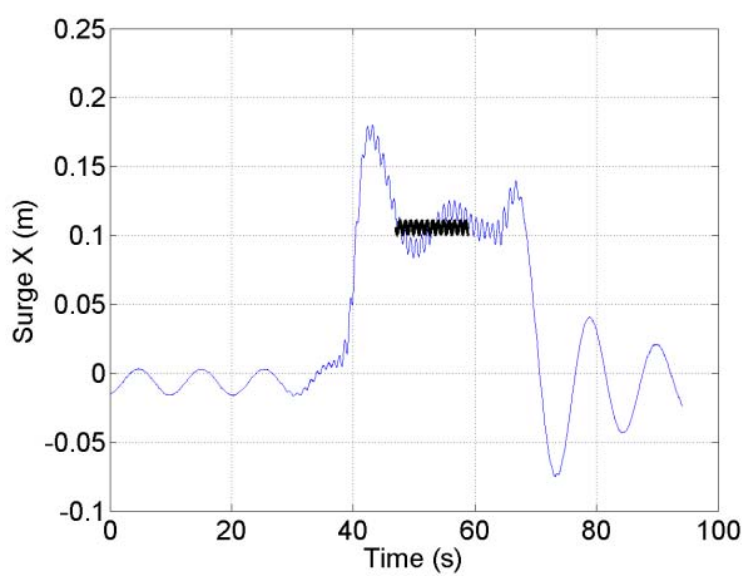

- correlation $<50 \%$

* $50 \%<$ correlation $<60 \%$

$\star 60 \%<$ correlation $<70 \%$

- $70 \%<$ correlation $<80 \%$

- $80 \%<$ correlation $<90 \%$

$+90 \%<$ correlation 
Fig. 9 Mean drift divided by the square of the wave amplitude for different wave frequencies and wave steepness values.

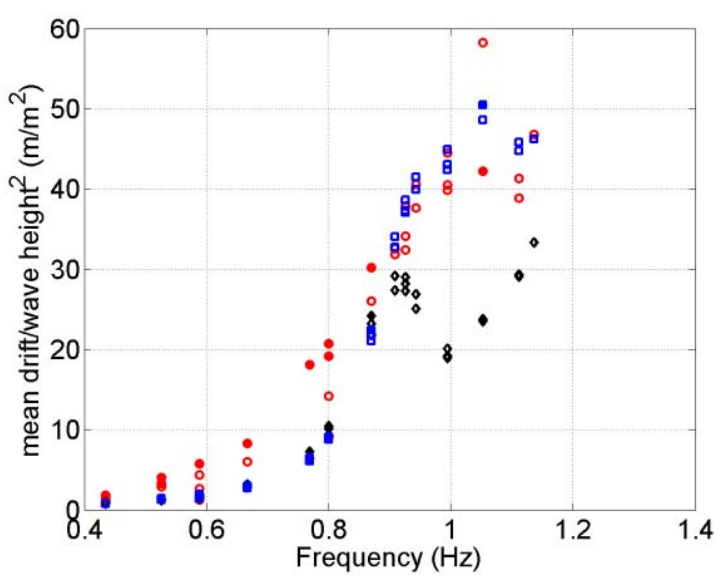
- experiment
- initial model
- corrected model 
Fig. 10 Motion RAOs for the surge, heave and pitch (from top to bottom): amplitudes (left) and phases (right)

(a)

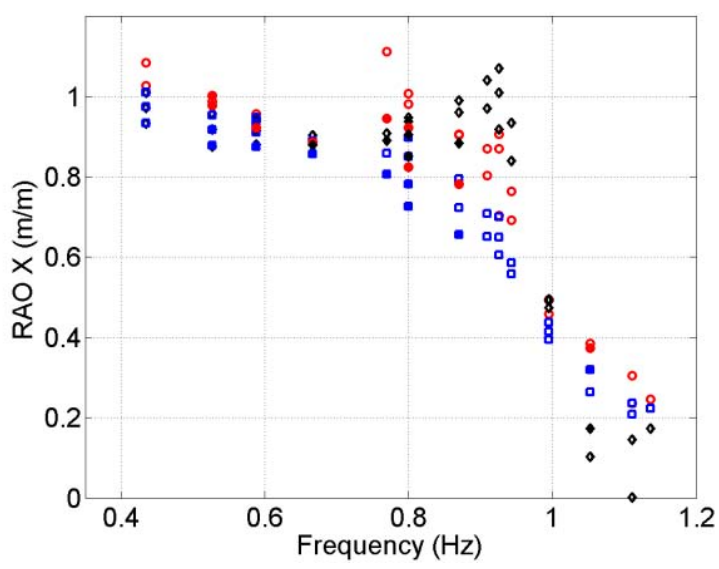

(c)

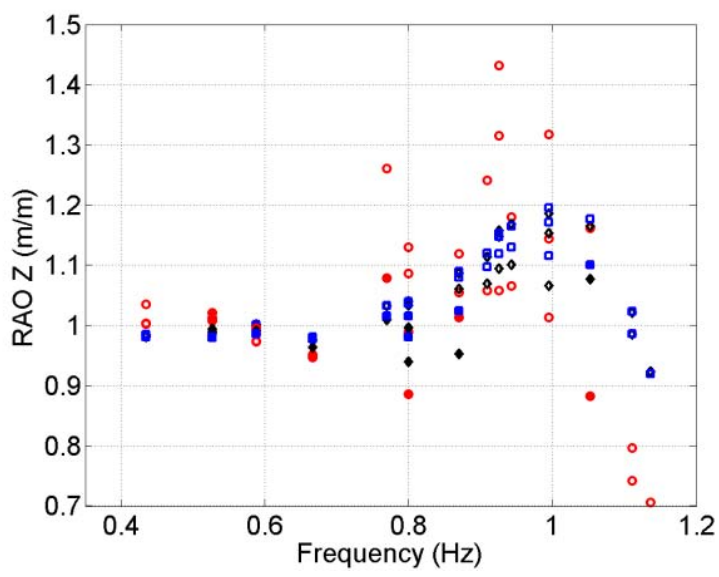

(e)

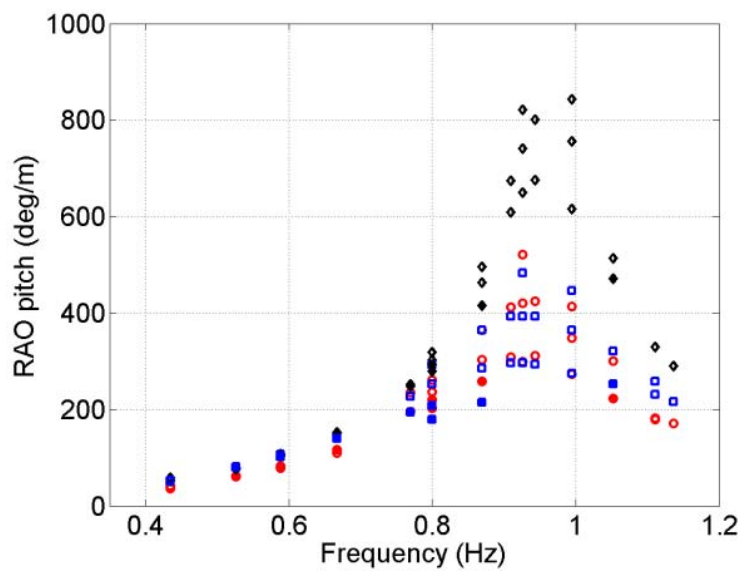

(b)

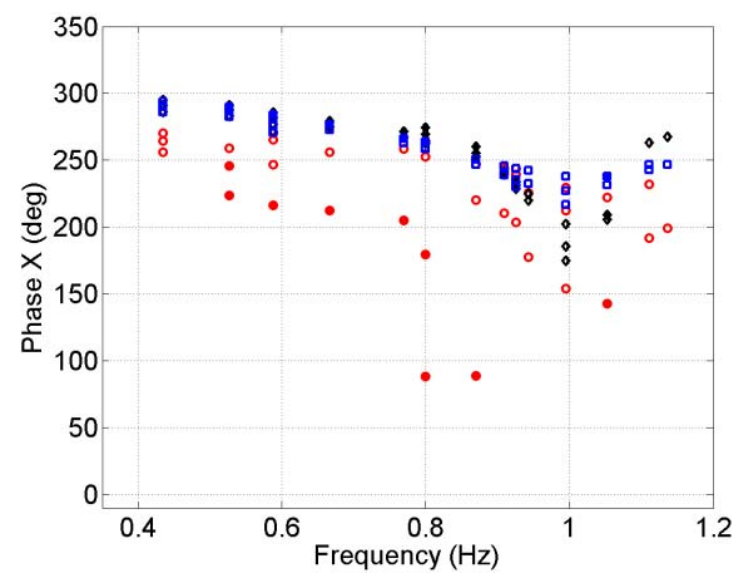

(d)

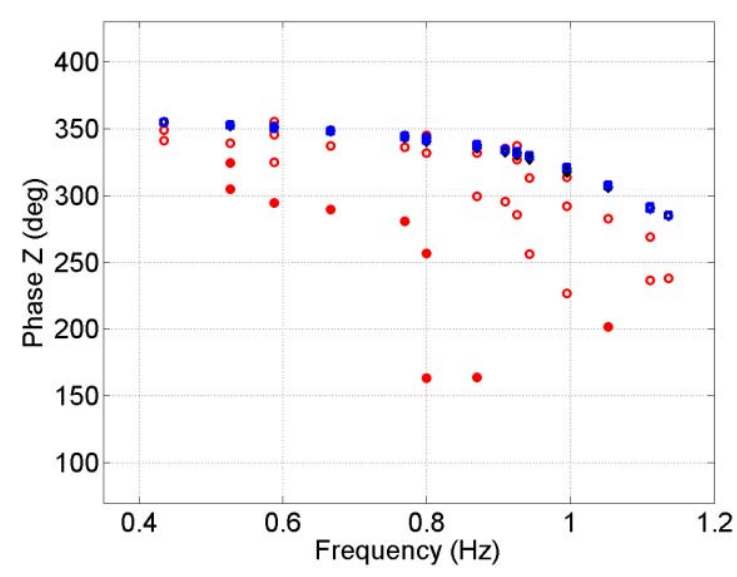

(f)

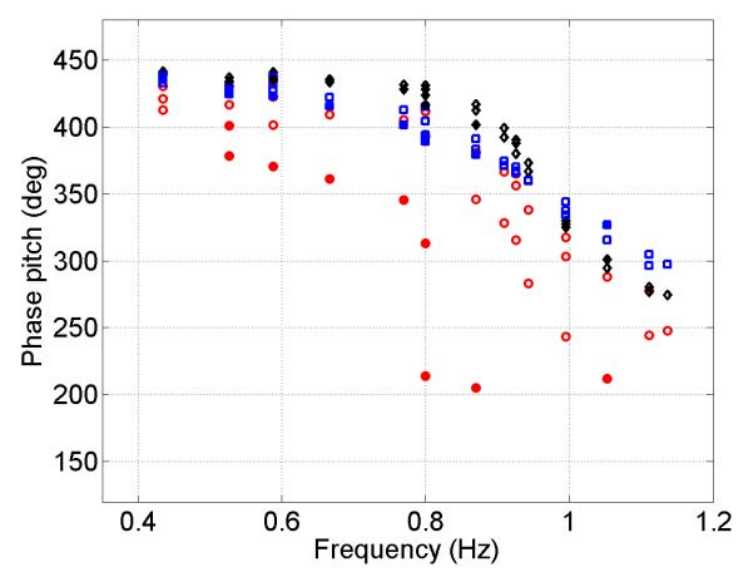
- experiment
- initial model
- corrected model 
Fig. 11 Regular wave tank test with the highest pitch RAO ( $H=0.03 \mathrm{~m}$ and $T=1.08 \mathrm{~s})$. a) Time series of the surface elevation and pitch motion $b$ ) Picture of the buoy at its maximum pitch RAO

(a)
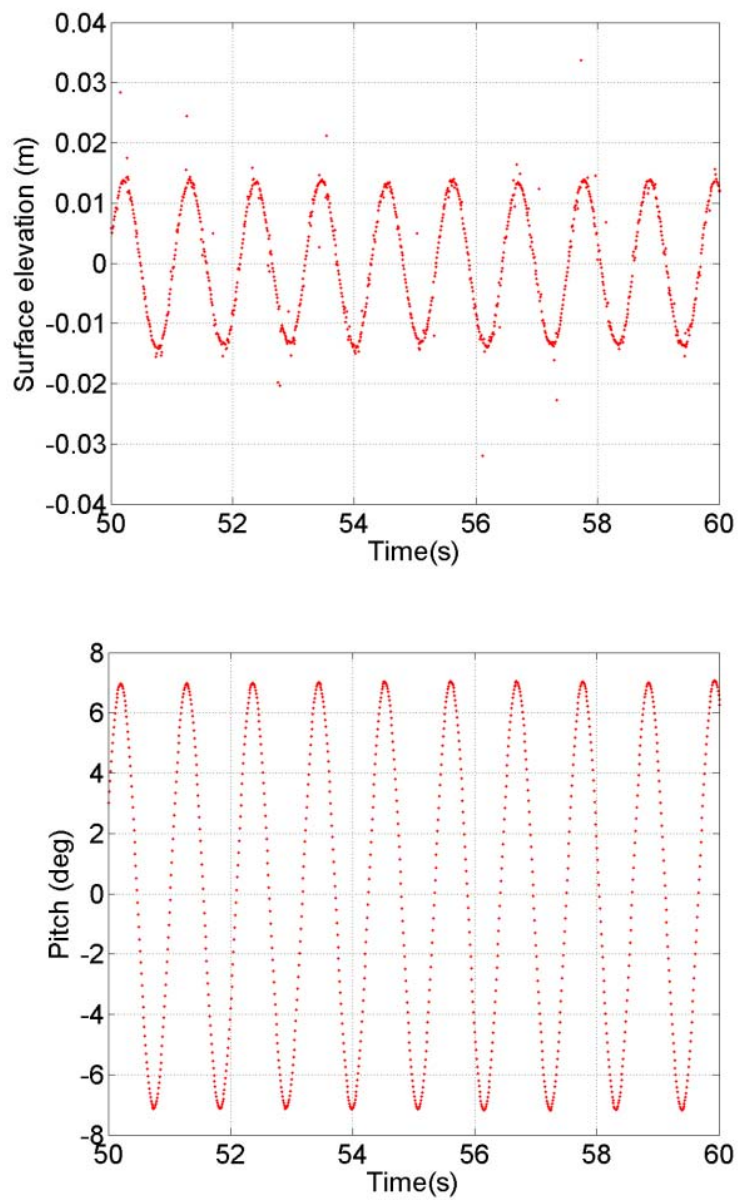

(b)

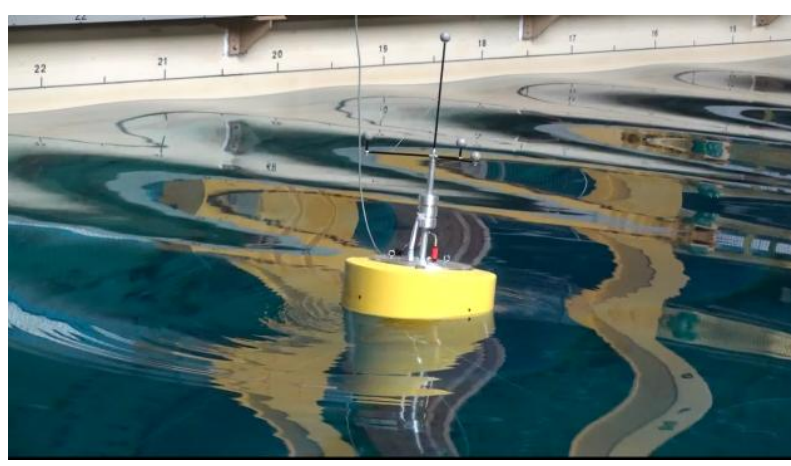


Fig. 12 Sensitivity analysis for the surge mean drift forces for the linear waves a) calculation of the mean drift for all sea states with the mean drift forces multiplied by different coefficients $b$ ) for a given sea state, calculation of the corrective mean drift force multiplicative factor which leads to equal experimental and numerical mean drift (here for $H=0.6 \mathrm{~m}$ and $T$ $=1.9 \mathrm{~s}$ ); c) for frequencies over $0.85 \mathrm{~Hz}$, fit of the corrective multiplicative factors; d) Corrected mean drift forces and smoothing of the values

(a)

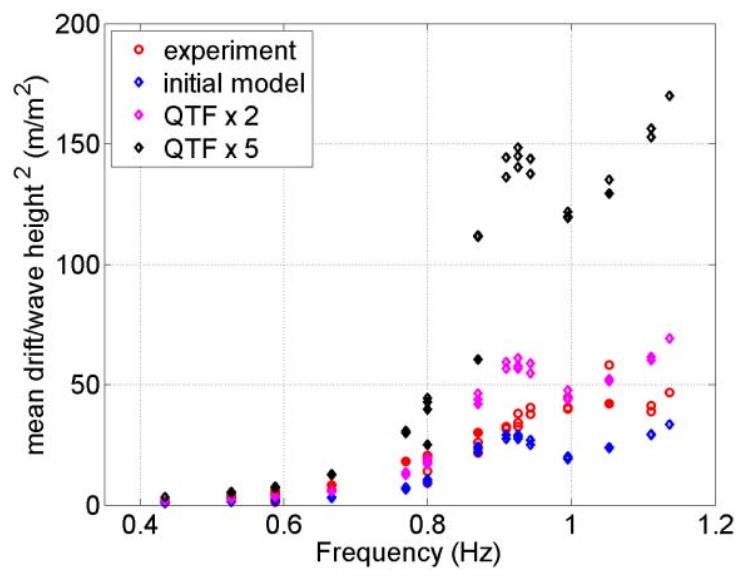

(c)

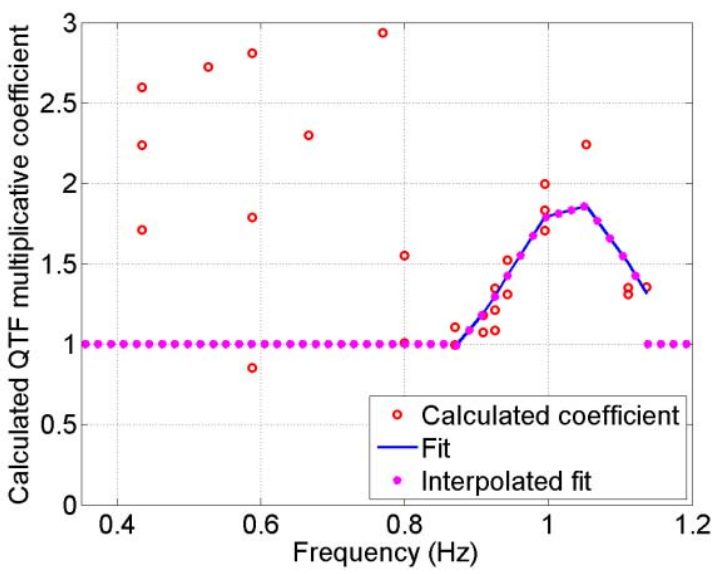

(b)

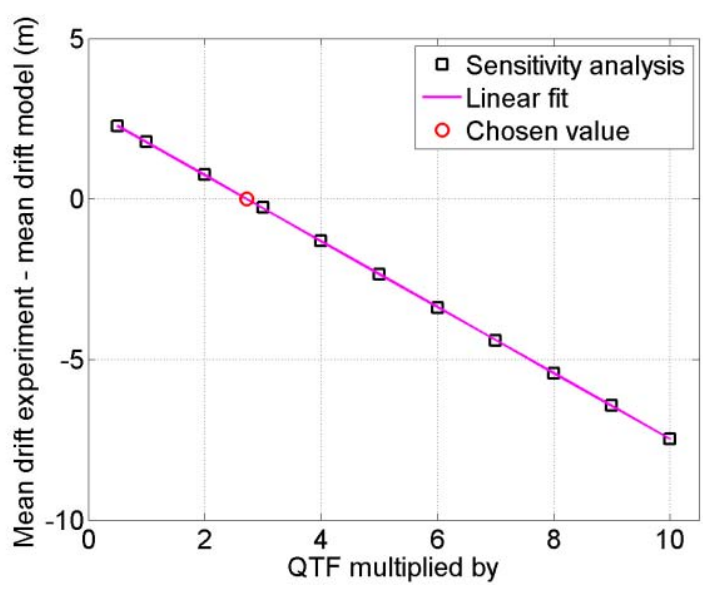

(d)

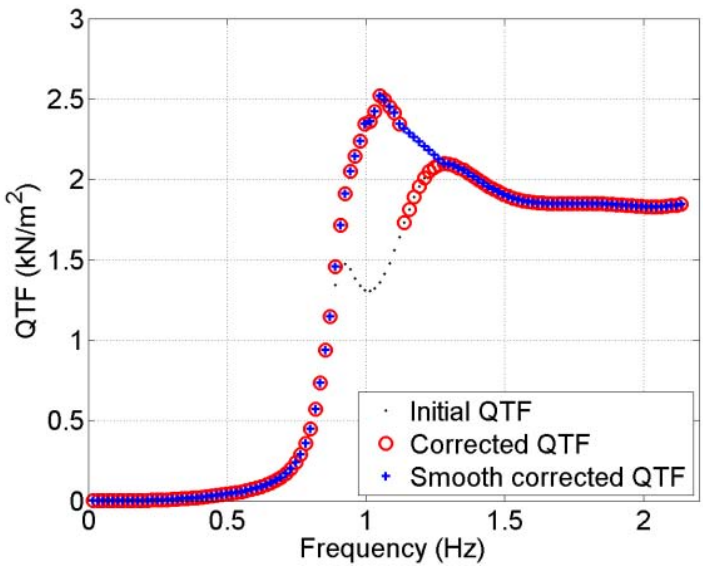


Fig. 13 Sensitivity analysis for the pitch additional quadratic damping: a) calculation of pitch RAO for different values of additional quadratic damping for all sea states. QD stands for additional quadratic damping; b) minimisation of the sum of the absolute value of the difference between experimental and numerical pitch RAOs

(a)

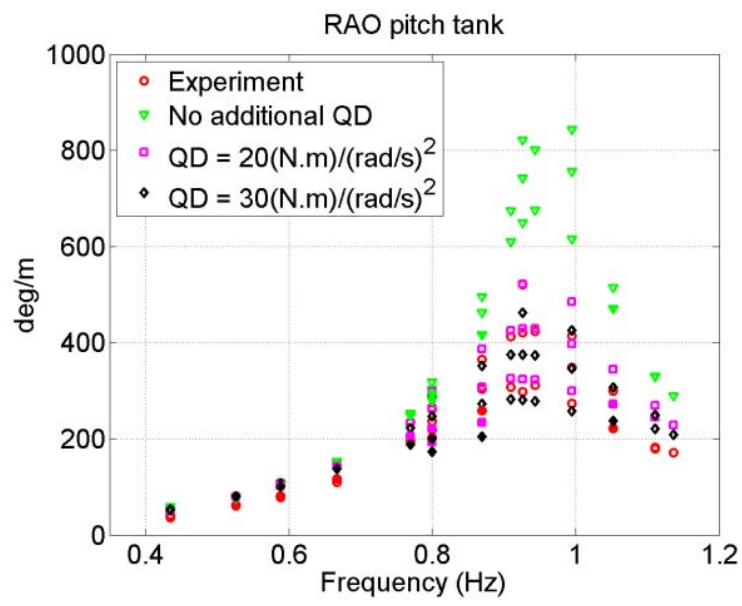

(b)

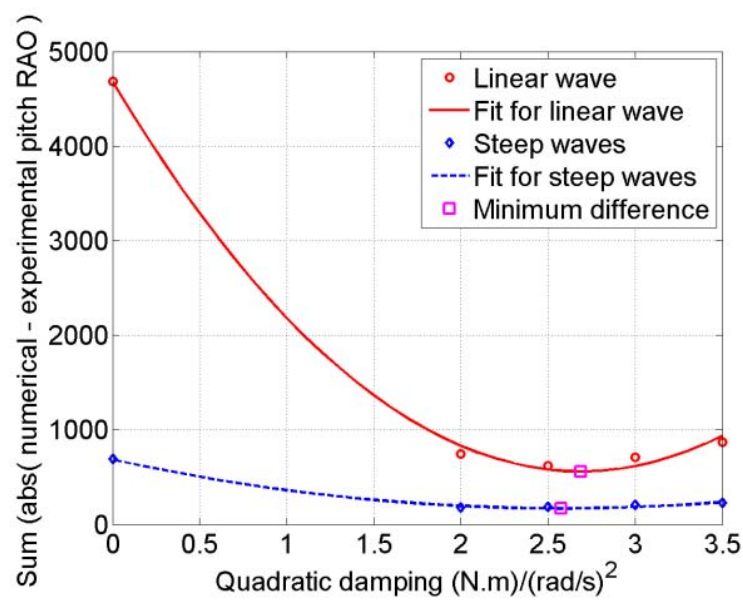


Fig. 14 Example of wave inputs for Case 2. The red dots are the signal measured during the experiment and the blue dots are for the corrected signal used as an input in the numerical model with different sampling frequencies: a) $100 \mathrm{~Hz}$, b) 10 $\mathrm{Hz}, \mathrm{c}) 4 \mathrm{~Hz}$

(a)

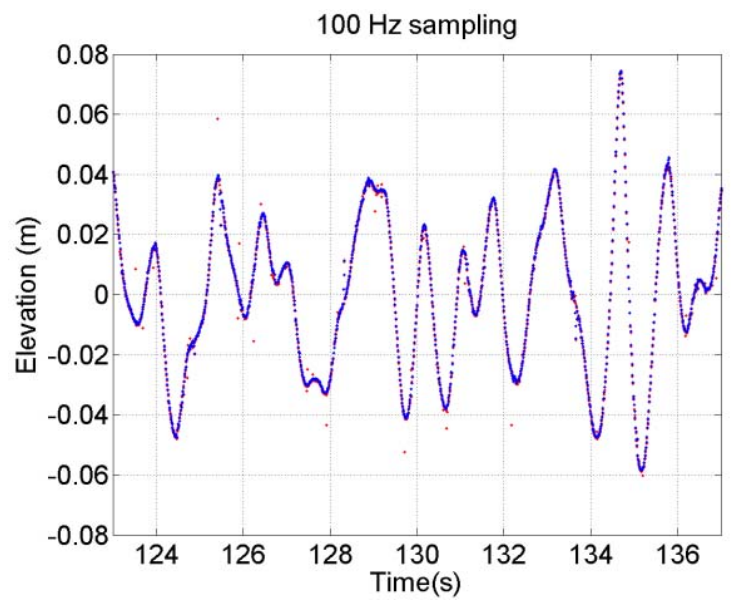

(b)

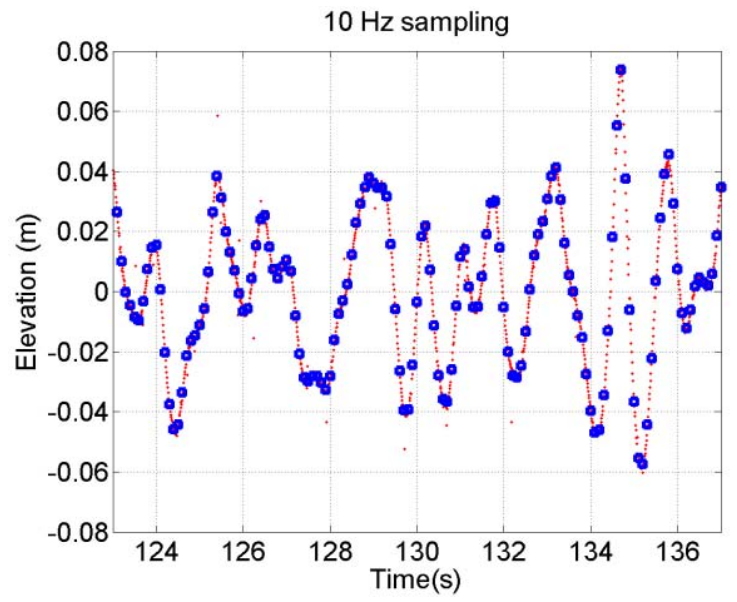

(c)

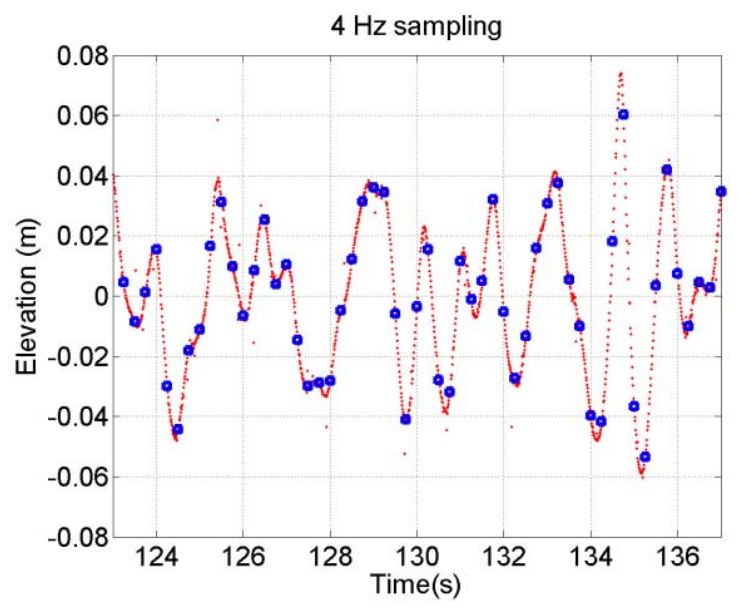


Fig. 15 Example of motion time series for Case 2: a) surge motion, b) heave motion and c) pitch motion. Red line: experiment, thick blue line: numerical model

(a)

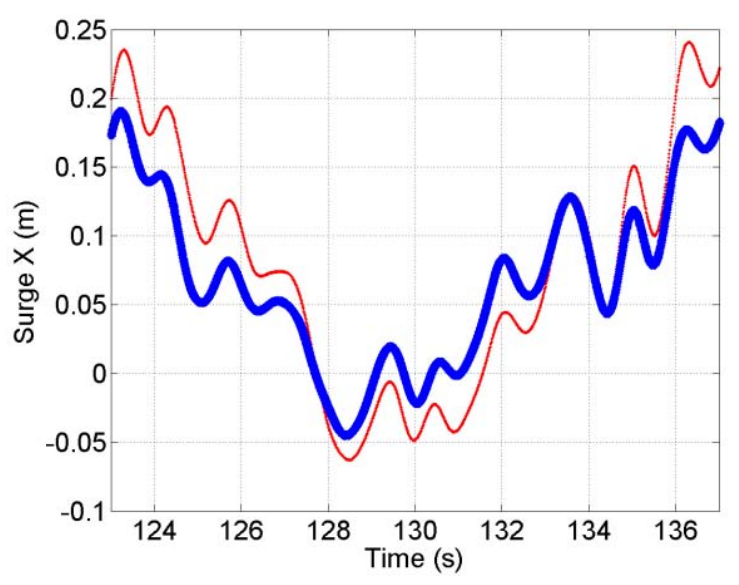

(b)

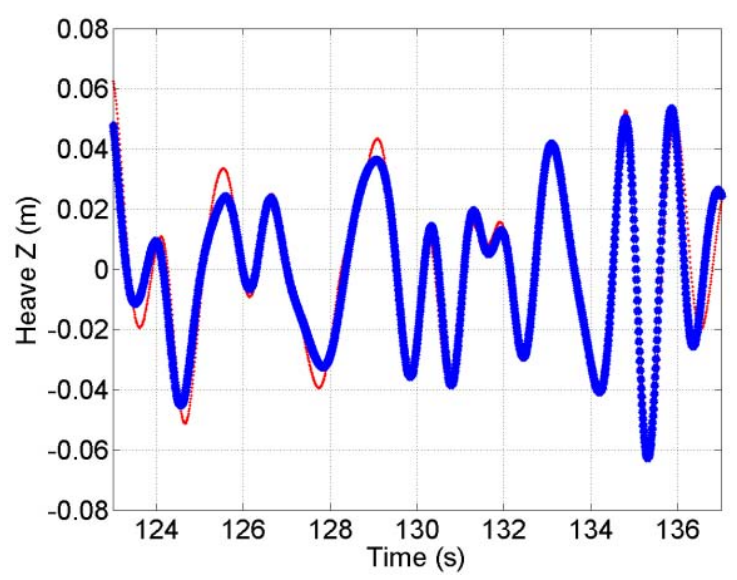

(c)

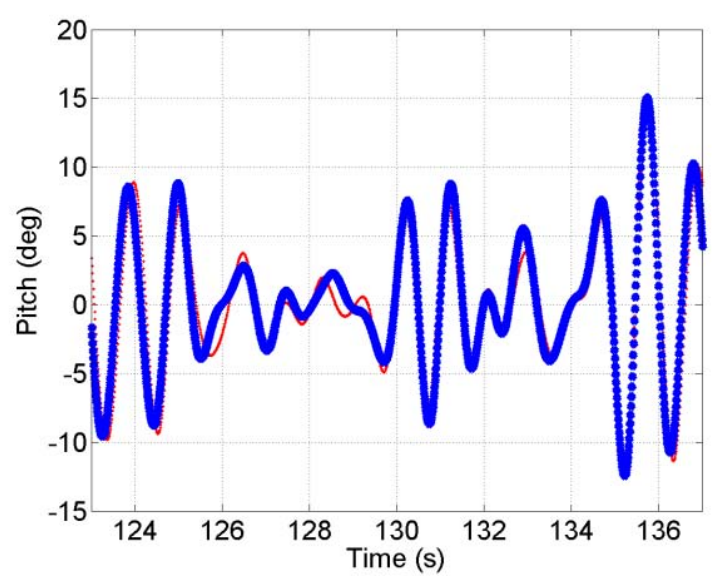

- experiment

- corrected model 
Fig. 16 Example of mooring load time series for Case 2: a) in the front line 1, b) in the back line 2, c) in the other front line 3. Red line: experiment, thick blue line: numerical model

(a)

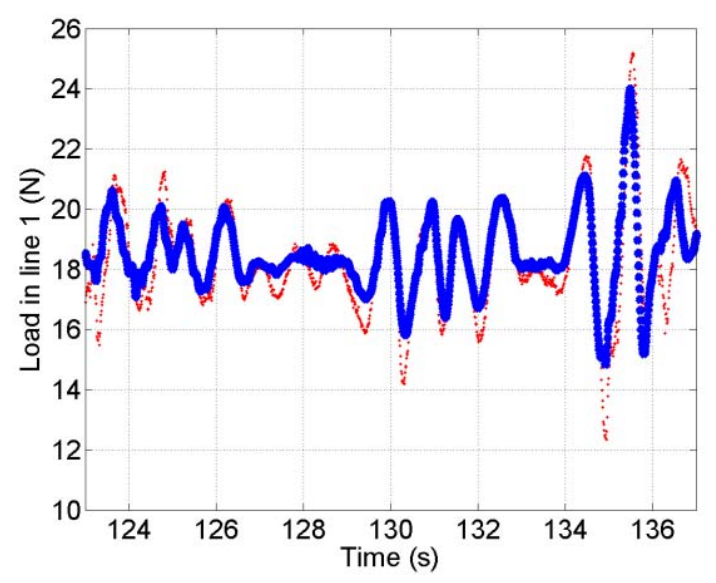

(b)

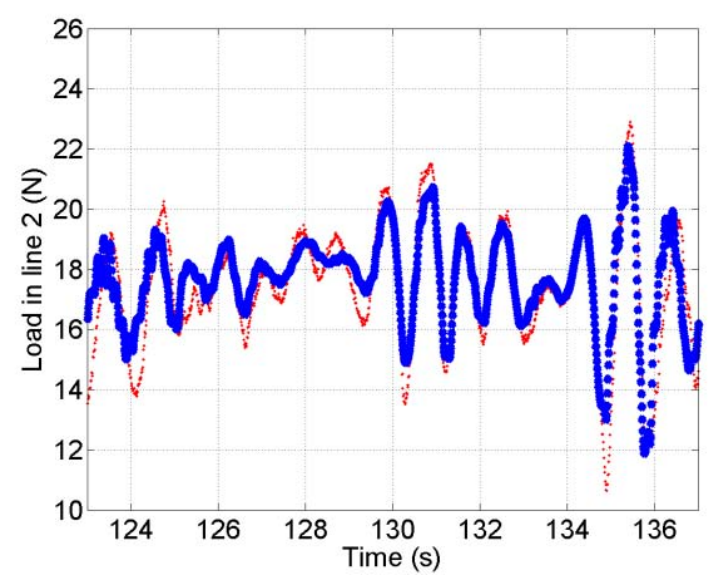

(c)

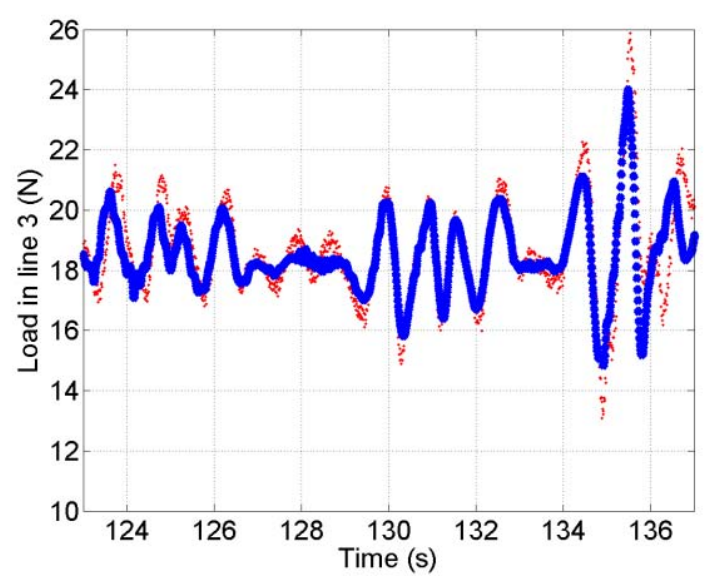

- experiment

- corrected model 
Fig. 17 Example of mooring load time series for Case 2 using different parameters for the numerical model: a) surge motion, b) heave motion, c) pitch motion, d) in the front line 1, e) in the back line 2, f) in the other front line 3 . Solid red line: experiment, blue dashed line: numerical model with full QTFs, black dotted line: numerical model using Newman's approximation with diagonal corrections

(a)

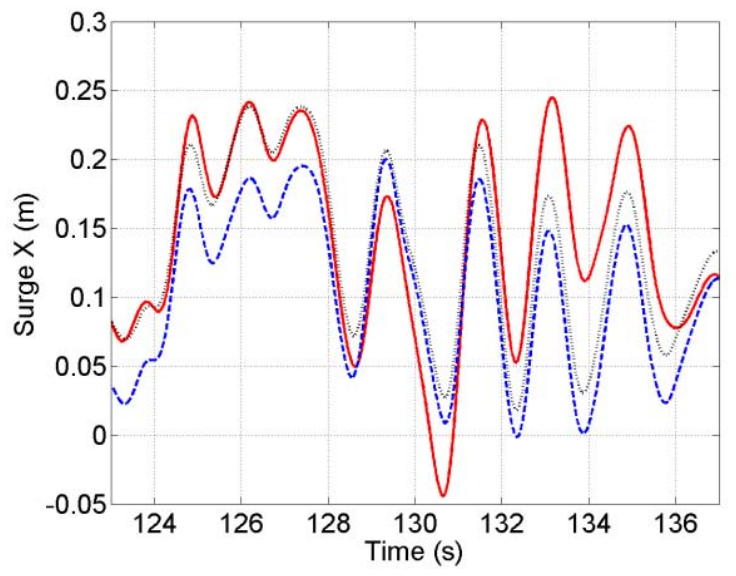

(b)

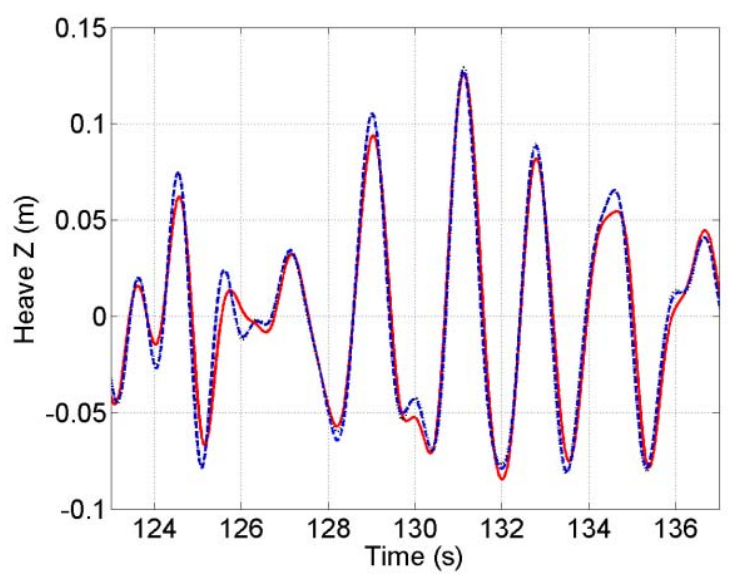

(c)

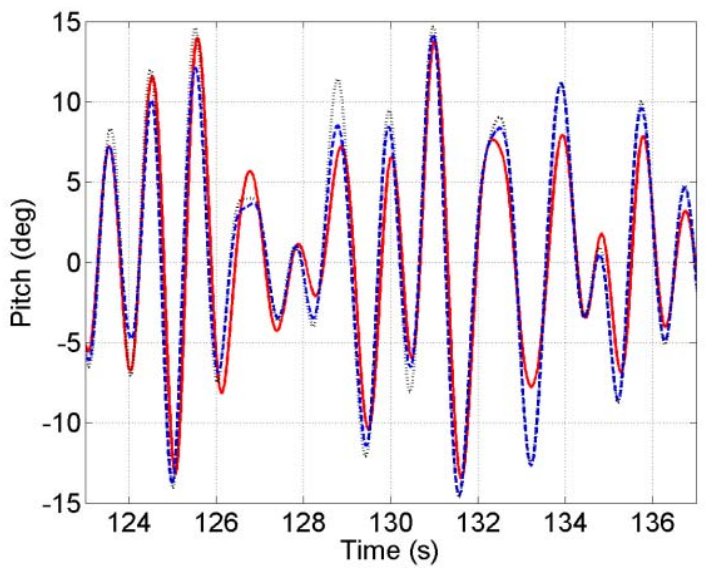

(d)

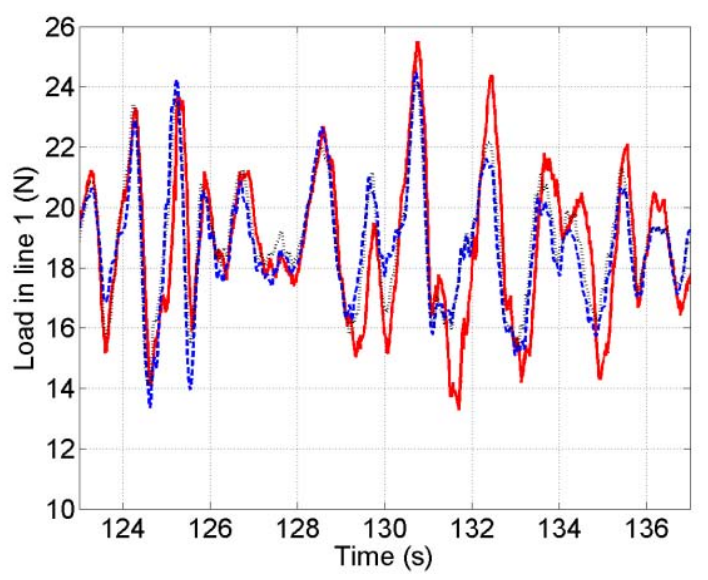

(e)

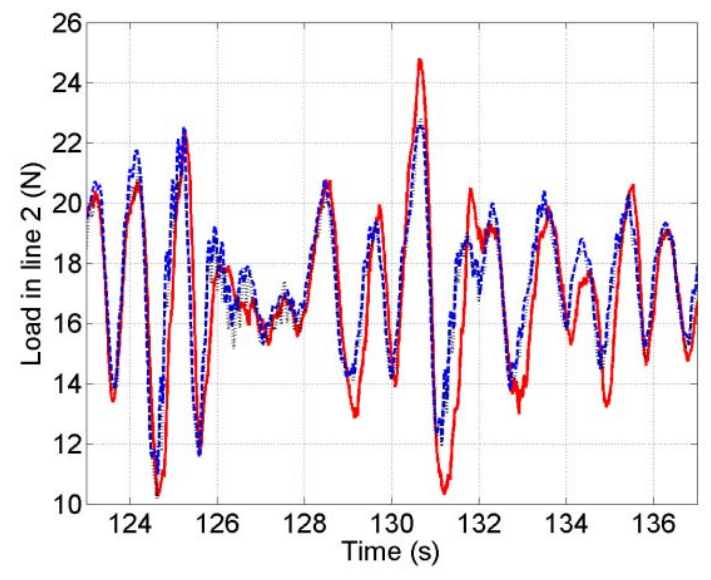

(f)

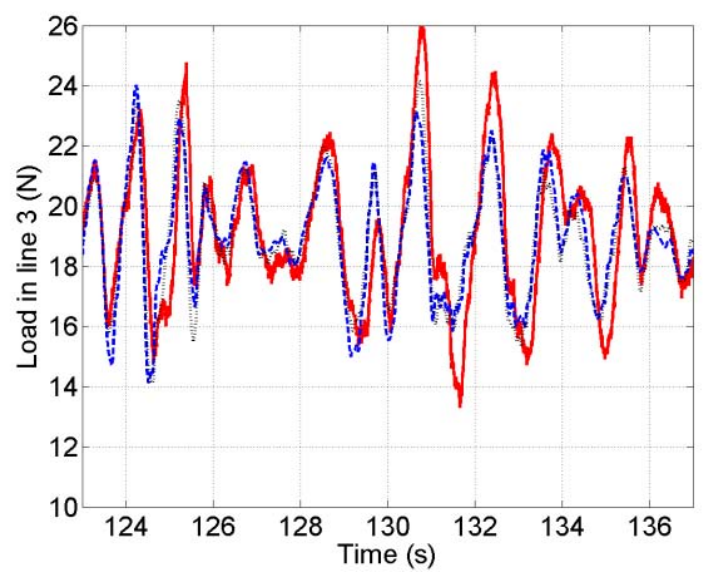


Fig. 18 Example of time series for Case 1 of mooring loads (a-c), motion (d-e) and waves (f) for the experiment in the tank (red thick) and the experiment in the field (blue dots). Results are shown at model scale. Red line: laboratory experiment, thick blue line: field tests

(a)

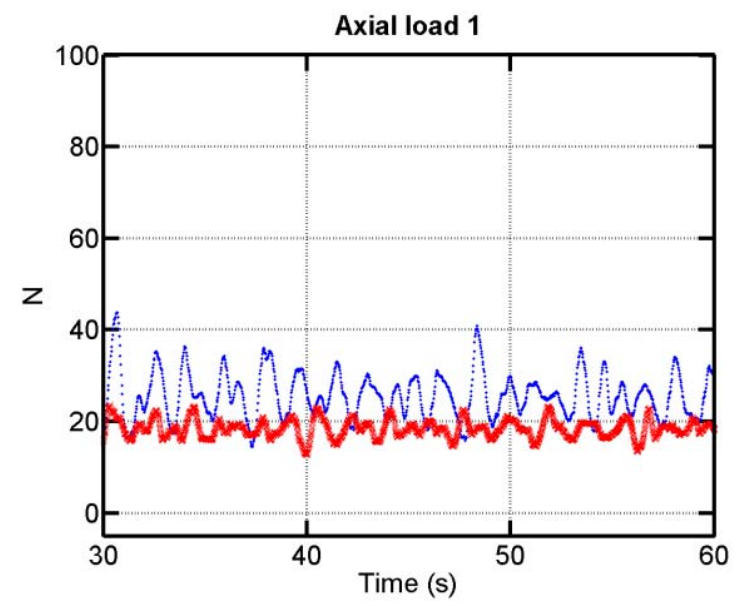

(b)

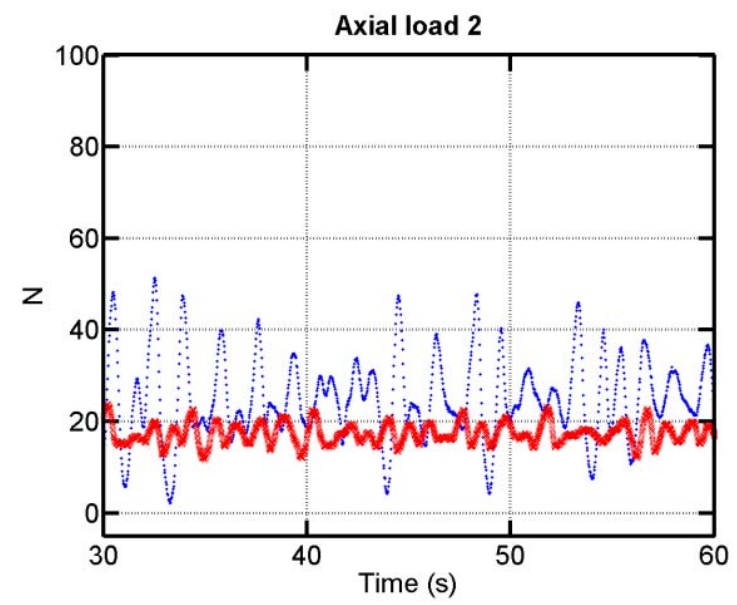

(c)

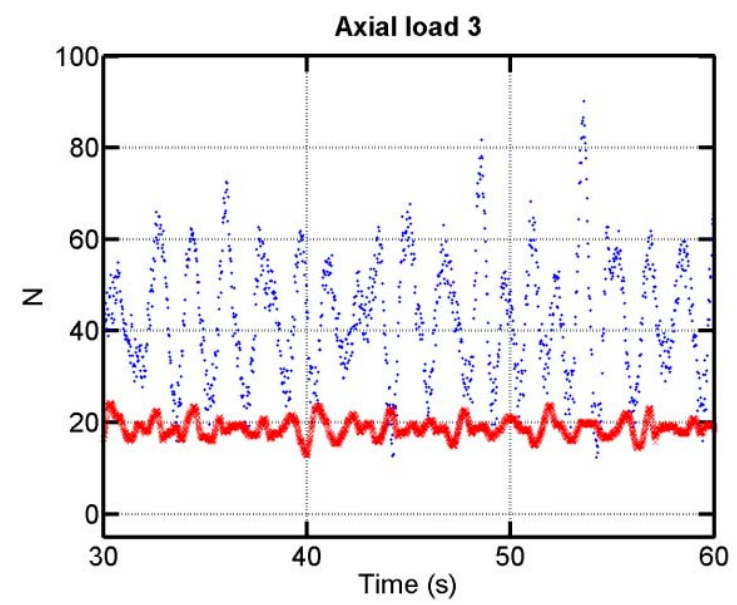

(d)

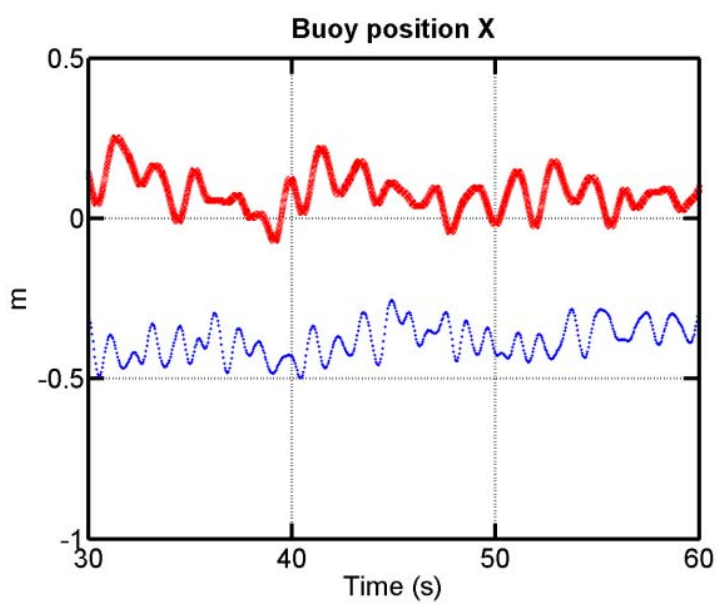

(e)

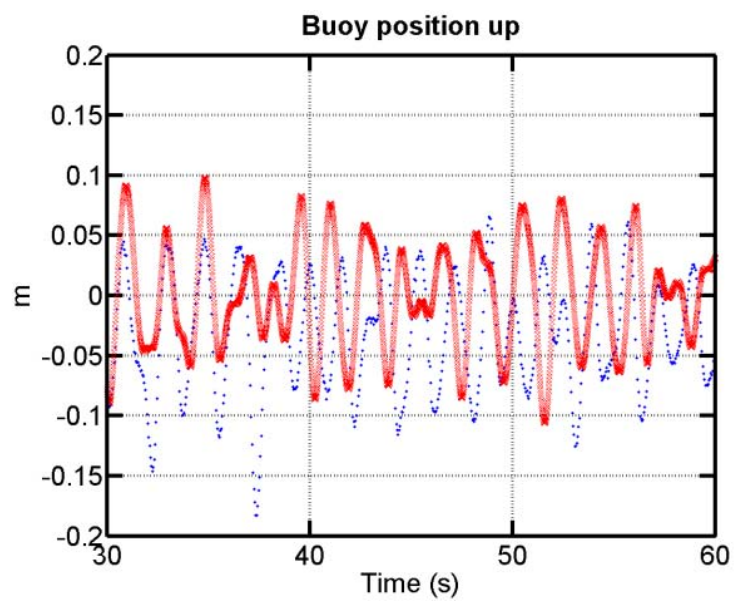

(f)

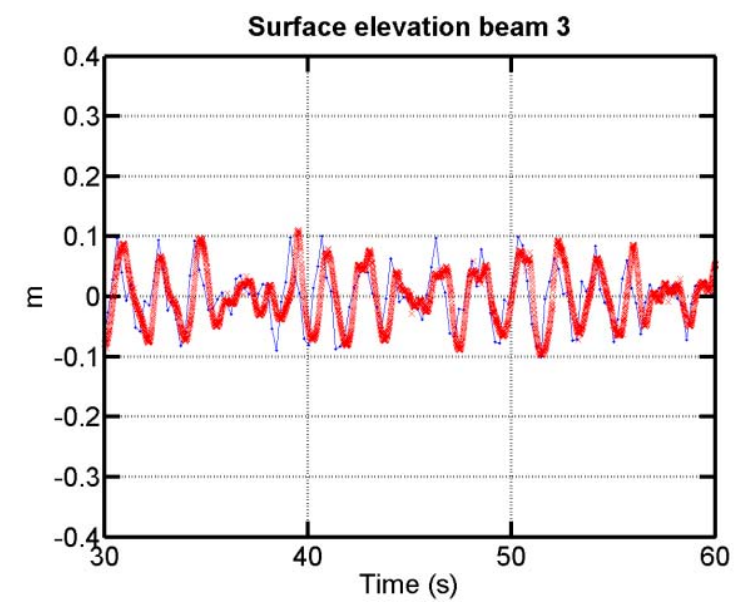


Fig. 19 Variations in motions and loads for Case 2 with models using different rope stiffness: a) Normalised correlation coefficient between the model with a given stiffness and the model used in this study; b) Normalised maximum mooring load with the models using different stiffness

(a)

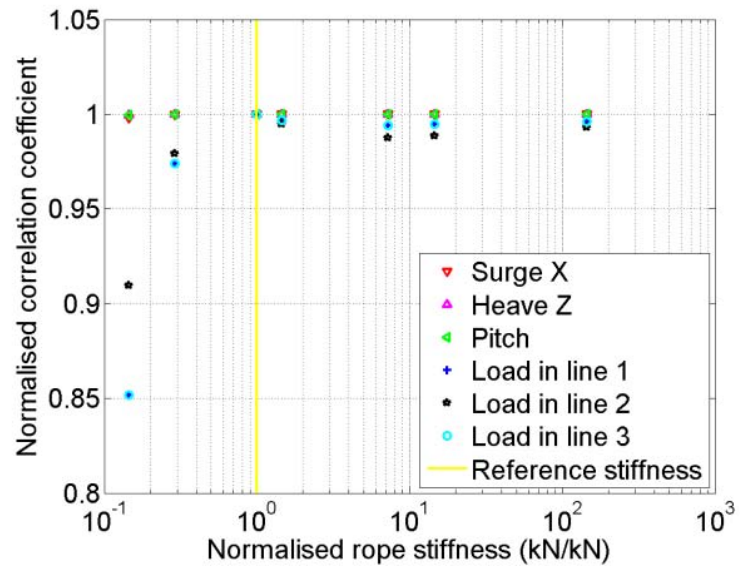

(b)

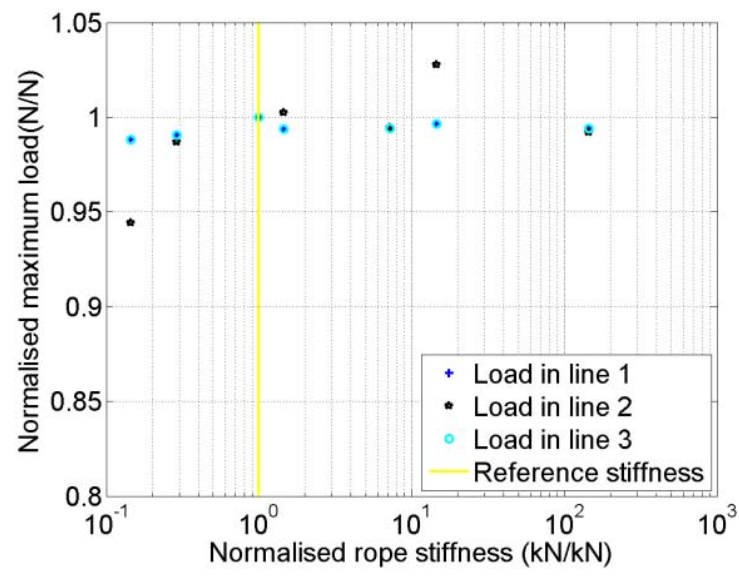


Table 1 Properties of the original mooring lines and of the simplified, scaled and truncated mooring lines where $C d_{n}$ and $C m_{n}$ are normal drag and inertia coefficients, $C d_{a}$ and $C m_{a}$ are axial drag and inertia coefficients, $\mathrm{T}=$ tonnes

\begin{tabular}{|c|c|c|c|c|c|c|c|c|c|c|c|}
\hline \multirow{2}{*}{$\begin{array}{l}\text { Section: } \\
\text { top(1) to } \\
\text { bottom (4) }\end{array}$} & \multirow{2}{*}{$\begin{array}{c}\text { Section } \\
\text { simplified } \\
\text { mooring }\end{array}$} & \multirow{2}{*}{$\begin{array}{l}\text { Components of } \\
\text { full scale SWMTF } \\
\text { mooring }\end{array}$} & \multirow[t]{2}{*}{$\begin{array}{l}\text { Length } \\
\text { (m) }\end{array}$} & \multirow{2}{*}{$\begin{array}{l}\text { Nominal } \\
\text { diameter } \\
\text { (m) }\end{array}$} & \multicolumn{2}{|c|}{ Mass $(\mathrm{kg} / \mathrm{m})$} & \multirow[t]{2}{*}{$\begin{array}{c}\text { Axial stiffness } \\
(E A, k N)\end{array}$} & \multicolumn{2}{|c|}{$\begin{array}{c}\text { Drag } \\
\text { coefficient }\end{array}$} & \multicolumn{2}{|c|}{$\begin{array}{c}\text { Inertia } \\
\text { coefficient }\end{array}$} \\
\hline & & & & & In air & $\begin{array}{l}\text { In } \\
\text { water }\end{array}$ & & $C d_{n}$ & $C d_{a}$ & $\mathrm{Cm}_{n}$ & $\mathrm{Cm}_{a}$ \\
\hline 1 & Chain & $\begin{array}{l}\text { Swinging arm } \\
4 \times 9.5 T \text { shackle } \\
\text { rope thimble } \\
\text { load cell } \\
10 T \text { swivel } \\
25 T \text { shackle } \\
\text { large rope thimble }\end{array}$ & 0.259 & 0.008 & 1.753 & 1.529 & 6464 & 1 & 0.4 & 1 & 0.07 \\
\hline 2 & Rope & $\begin{array}{l}\text { Nylon rope: Bridon } \\
\text { superline } 44 \mathrm{~mm} \\
\text { diameter }\end{array}$ & 4.0 & 0.009 & 0.024 & 0.00425 & $\begin{array}{l}\text { Scaled value for } \\
\text { full scale } \\
\text { facility:7.1-7.8 } \\
\text { Tank (mean): } \\
10.873\end{array}$ & 1.6 & 0 & 1 & 0 \\
\hline 3 & Chain & $\begin{array}{l}2 \times 9.5 \mathrm{~T} \text { shackle } \\
10 \mathrm{~T} \text { swivel } \\
25 \mathrm{~T} \text { shackle } \\
\text { large rope thimble }\end{array}$ & 0.126 & 0.006 & 1.786 & 1.558 & $3.636 \mathrm{e} 6$ & 1 & 0.4 & 1 & 0.07 \\
\hline 4 & Chain & $\begin{array}{l}\text { DN24 openlink } \\
\text { chain } \\
\text { 9.5T shackle }\end{array}$ & 5.672 & 0.0049 & 0.4609 & 0.402 & $2.0505 e 6$ & 1 & 0.4 & 1 & 0.08 \\
\hline
\end{tabular}


Table 2 Full scale and model buoy properties and difference with theoretical values where COG=centre of gravity

\begin{tabular}{|c|c|c|c|c|}
\hline & Full scale SWMTF values & Theoretical scaled values & Measured scaled values & Relative error \\
\hline $\begin{array}{l}\text { Mass }(\mathrm{kg}) \\
\text { Distance between COG and } \\
\text { bottom of keel }(\mathrm{m})\end{array}$ & $\begin{array}{l}3108 \\
1.13\end{array}$ & $\begin{array}{l}24.86 \\
0.2260\end{array}$ & $\begin{array}{l}24.86 \\
0.2262\end{array}$ & $\begin{array}{l}0 \% \\
0.09 \%\end{array}$ \\
\hline Moment of inertia $I_{x x}\left(\mathrm{~kg} \cdot \mathrm{m}^{2}\right)$ & 4260.75 & 1.3634 & 1.4141 & $3.72 \%$ \\
\hline Moment of inertia $I_{z z}\left(\mathrm{~kg} \cdot \mathrm{m}^{2}\right)$ & 1178.83 & 0.3772 & 0.3963 & $5.06 \%$ \\
\hline
\end{tabular}


Table 3 Results for the surge decay tests: amplitude of release and after one oscillation, natural period $T_{m}$, linear damping $p_{1}$ and quadratic damping $p_{2}$ and norm of the residuals associated with the damping linear fit

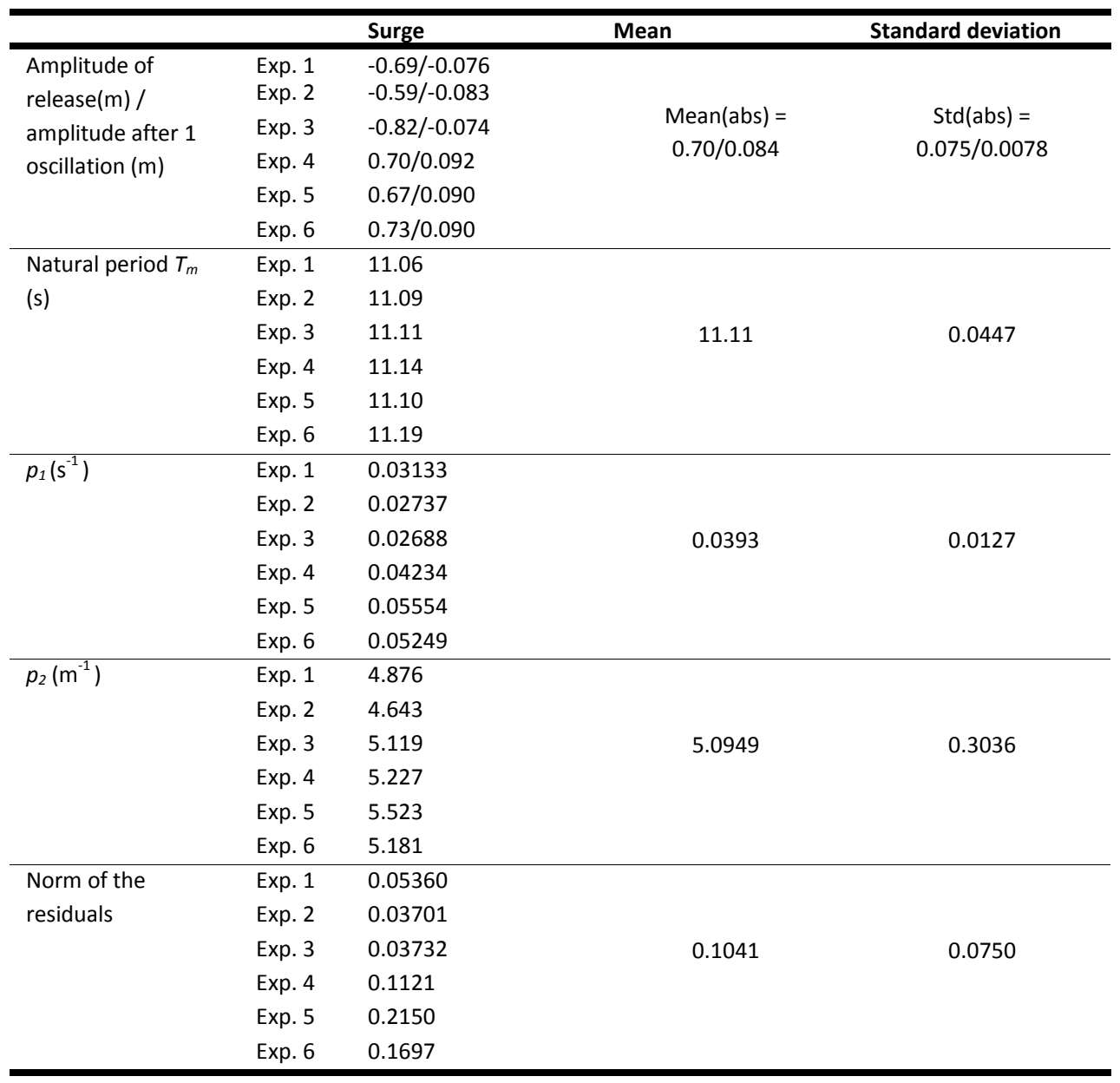


Table 4 Results for the pitch decay tests: amplitude of release, natural period $T_{m}$ linear damping $p_{1}$ and quadratic damping $p_{2}$ and norm of the residuals associated with the damping linear fit

\begin{tabular}{|c|c|c|c|c|}
\hline & & Pitch & Mean & $\begin{array}{l}\text { Standard } \\
\text { deviation }\end{array}$ \\
\hline \multirow{5}{*}{$\begin{array}{l}\text { Amplitude of } \\
\text { release }\left({ }^{\circ}\right) / \\
\text { amplitude after } 1 \\
\text { oscillation }\left({ }^{\circ}\right)\end{array}$} & Exp. 1 & $-7.3 /-4.0$ & \multirow{5}{*}{$\begin{array}{c}\text { Mean }(\mathrm{abs})= \\
3.7 / 2.3\end{array}$} & \multirow{5}{*}{$\begin{array}{c}\text { Std(abs) }= \\
2.1 / 1.1\end{array}$} \\
\hline & Exp. 2 & $-3.0 /-2.1$ & & \\
\hline & Exp. 3 & $-3.6 /-2.4$ & & \\
\hline & Exp. 4 & $-3.2 /-2.2$ & & \\
\hline & Exp. 5 & $1.6 / 0.93$ & & \\
\hline \multirow{5}{*}{$\begin{array}{l}\text { Natural period } T_{m} \\
\text { (s) }\end{array}$} & Exp. 1 & 1.070 & \multirow{5}{*}{ / } & \multirow{5}{*}{ / } \\
\hline & Exp. 2 & 1.080 & & \\
\hline & Exp. 3 & 1.095 & & \\
\hline & Exp. 4 & 1.120 & & \\
\hline & Exp. 5 & 1.088 & & \\
\hline \multirow[t]{5}{*}{$p_{1}\left(\mathrm{~s}^{-1}\right)$} & Exp. 1 & / & \multirow{5}{*}{ / } & \multirow{5}{*}{ / } \\
\hline & Exp. 2 & / & & \\
\hline & Exp. 3 & -0.5105 & & \\
\hline & Exp. 4 & / & & \\
\hline & Exp. 5 & 0.01242 & & \\
\hline \multirow[t]{5}{*}{$p_{2}\left(\operatorname{rad}^{-1}\right)$} & Exp. 1 & / & \multirow{5}{*}{ / } & \multirow{5}{*}{ / } \\
\hline & Exp. 2 & / & & \\
\hline & Exp. 3 & 0.9197 & & \\
\hline & Exp. 4 & / & & \\
\hline & Exp. 5 & 0.3268 & & \\
\hline Norm of the & Exp. 1 & / & \multirow{5}{*}{ / } & \multirow{5}{*}{ / } \\
\hline \multirow[t]{4}{*}{ residuals } & Exp. 2 & / & & \\
\hline & Exp. 3 & 0.8512 & & \\
\hline & Exp. 4 & / & & \\
\hline & Exp. 5 & 0.1585 & & \\
\hline
\end{tabular}


Table 5 Comparison of experimental and numerical results: natural period $T_{m}$ linear damping $p_{1}$ and quadratic damping $p_{2}$ for surge decay

\begin{tabular}{llll}
\hline & $\begin{array}{l}\text { Values measured from } \\
\text { tank }\end{array}$ & $\begin{array}{l}\text { Initial numerical model: } \\
\text { value/relative error }\end{array}$ & $\begin{array}{l}\text { Corrected numerical } \\
\text { model: value/relative } \\
\text { error }\end{array}$ \\
\hline Natural Period $T_{m}(\mathrm{~s})$ & $\mathbf{1 1 . 1 1}$ & $10.68 / 4 \%$ & $11.20 / 1 \%$ \\
$p_{1}\left(\mathrm{~s}^{-1}\right)$ & $\mathbf{0 . 0 3 9 3}$ & $0.0008 / 98 \%$ & $0.0426 / 8 \%$ \\
$p_{2}\left(\mathrm{~m}^{-1}\right)$ & $\mathbf{5 . 0 9 4 9}$ & $1.0503 / 79 \%$ & $4.7488 / 7 \%$ \\
\hline
\end{tabular}


Table 6 Correction implemented on added mass, linear damping $p_{1}$ and quadratic damping $p_{2}$ for the surge motion

\begin{tabular}{lll}
\hline $\begin{array}{l}\text { Added mass } \\
\text { multiplied by }\end{array}$ & $\begin{array}{l}\text { Additional Linear } \\
\text { damping } \mathrm{p}_{\mathbf{1}}\left(\mathrm{s}^{-1}\right)\end{array}$ & $\begin{array}{l}\text { Additional Quadratic } \\
\text { Damping } \mathrm{p}_{2}\left(\mathrm{~m}^{-1}\right)\end{array}$ \\
\hline 1.3262 & 0.0487 & 4.2639 \\
\hline
\end{tabular}


Table 7 Statistical properties of the irregular sea states as calculated by WavesMon, the ADCP firmware using the field data, and plot of the field data spectrum with WAFO function dat2spec [20], using default frequency smoothing (parzen window function on the estimated autocovariance function)

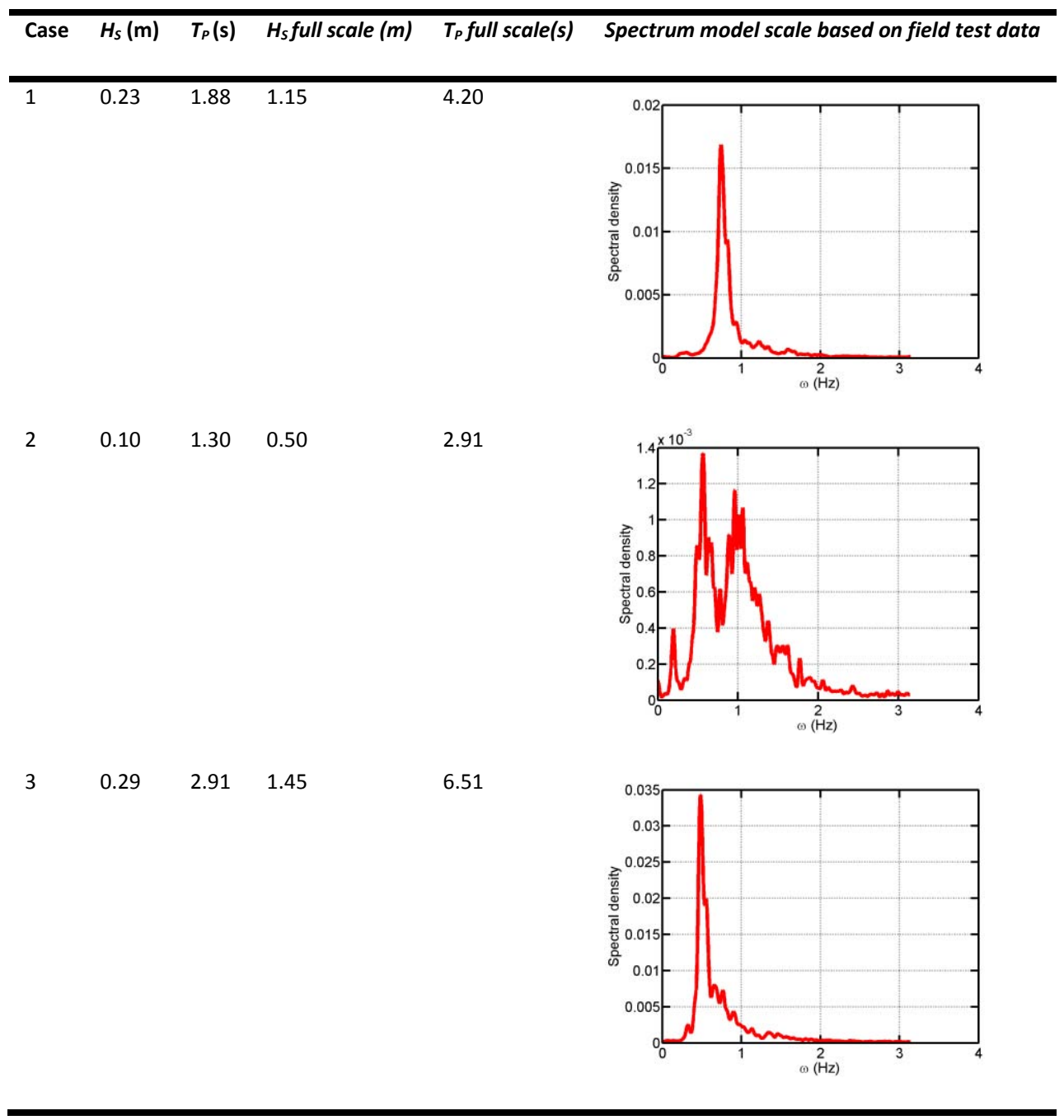


Table 8 Comparison of experimental measurements and numerical model results for the wave elevation, buoy motions and mooring loads

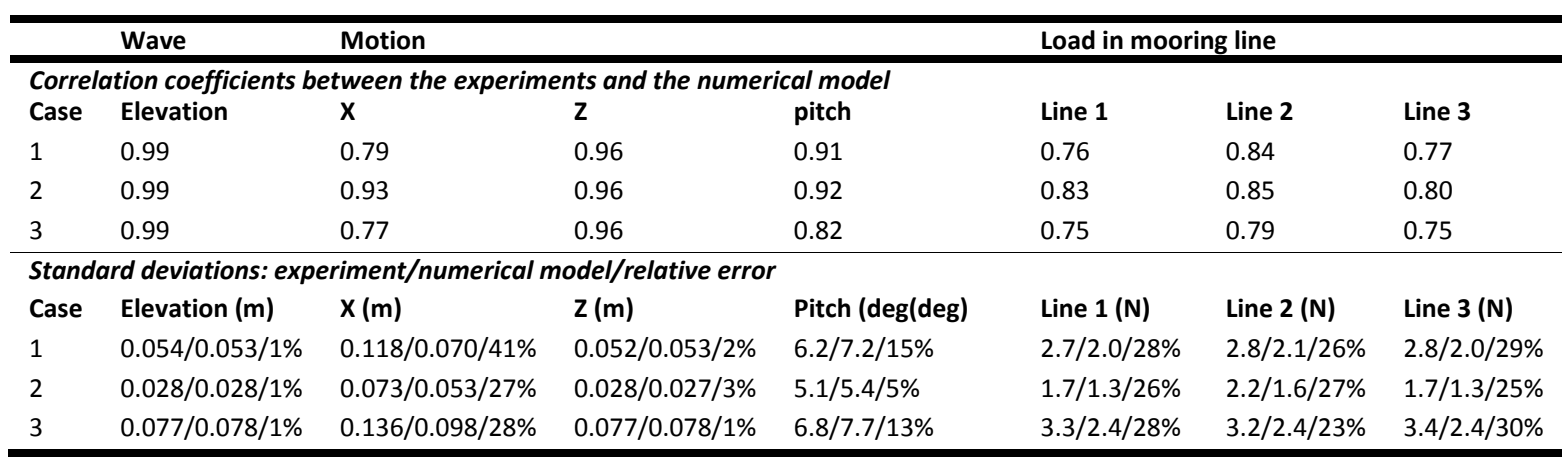


Table 9 Comparison of maximum mooring loads for the different cases and the different mooring lines

\begin{tabular}{lllll}
\hline Case & & Line 1 (N) & Line 2 (N) & Line 3 (N) \\
\hline 1 & Experiment & 33.9 & 31.2 & 34.9 \\
& Corrected Model. & 28.9 & 25.2 & 28.9 \\
& Relative error & $15 \%$ & $8 \%$ & $12 \%$ \\
\hline 2 & Experiment & 27.4 & 25.0 & 27.7 \\
& Corrected Model. & 25.9 & 23.7 & 28.2 \\
& Relative error & $17 \%$ & $5 \%$ & $6 \%$ \\
\hline 3 & Experiment & 32.9 & 29.8 & 33.7 \\
& Corrected Model. & 28.9 & 25.2 & 28.9 \\
& Relative error & $17 \%$ & $9 \%$ & $14 \%$ \\
\hline
\end{tabular}


Table 10 Comparison of correlation coefficients between the numerical model results using different sampling frequencies for the wave input and the experimental results for the wave elevation, buoy motions and mooring loads for Case 1

\begin{tabular}{|c|c|c|c|c|c|c|c|}
\hline \multicolumn{2}{|c|}{ Wave } & \multicolumn{2}{|l|}{ Motion } & \multicolumn{4}{|c|}{ Load in mooring line } \\
\hline \multicolumn{8}{|c|}{ Correlation coefficients between the experiments and the numerical model/relative error with $100 \mathrm{~Hz}$ input } \\
\hline Freq & Elevation & $\mathbf{x}$ & $\mathbf{Z}$ & pitch & Line 1 & Line 2 & Line 3 \\
\hline $4 \mathrm{~Hz}$ & $0.9927 / 0.40 \%$ & $0.8041 / 2.15 \%$ & $0.9629 / 0.01 \%$ & $0.9089 / 0.12 \%$ & $0.7611 / 0.17 \%$ & $0.8396 / 0.25 \%$ & $0.7728 / 0.03 \%$ \\
\hline 10 & $0.9962 / 0.05 \%$ & $0.8122 / 1.17 \%$ & $0.9626 / 0.02 \%$ & $0.9075 / 0.03 \%$ & $0.7589 / 0.12 \%$ & $0.8408 / 0.11 \%$ & $0.7719 / 0.09 \%$ \\
\hline 100 & $0.9967 / 0 \%$ & $0.8218 / 0 \%$ & $0.9628 / 0 \%$ & $0.9078 / 0 \%$ & $0.7598 / 0 \%$ & $0.8417 / 0 \%$ & $0.7726 / 0 \%$ \\
\hline
\end{tabular}


Table 11 Comparison of correlation coefficients between the numerical model results using the Newman's approximation (before and after correction of the mean drift) and using the full QTFs for the buoy motions and mooring loads for Case 1

\begin{tabular}{|c|c|c|c|c|c|c|}
\hline & \multicolumn{2}{|l|}{ Motion } & \multicolumn{4}{|c|}{ Load in mooring line } \\
\hline \multicolumn{7}{|c|}{ Correlation coefficients between the experiment and the numerical models } \\
\hline Method of calculation & $\mathbf{x}$ & $\mathbf{Z}$ & pitch & Line 1 & Line 2 & Line 3 \\
\hline Newman's approximation original & 0.8087 & 0.9628 & 0.9094 & 0.7593 & 0.8414 & 0.7702 \\
\hline Newman's approximation corrected & 0.8041 & 0.9629 & 0.9089 & 0.7611 & 0.8396 & 0.7728 \\
\hline Full QTFs & 0.7281 & 0.9627 & 0.7569 & 0.7206 & 0.8040 & 0.7239 \\
\hline Full QTFs diagonal corrected & 0.7189 & 0.9627 & 0.7320 & 0.7104 & 0.8046 & 0.7189 \\
\hline \multicolumn{7}{|c|}{ Mean values/relative error with experiment } \\
\hline Method of calculation & $X(m)$ & & & Line $1(N)$ & Line $2(N)$ & Line $3(\mathbf{N})$ \\
\hline Newman's approximation original & $0.099 / 23 \%$ & & & $18.7 / 1 \%$ & $17.4 / 2 \%$ & $18.7 / 2 \%$ \\
\hline Newman's approximation corrected & $0.118 / 9 \%$ & & & $18.8 / 1 \%$ & $17.2 / 1 \%$ & $18.8 / 1 \%$ \\
\hline Full QTFs & $0.099 / 23 \%$ & & & $18.9 / 2 \%$ & $17.6 / 3 \%$ & $18.9 / 0 \%$ \\
\hline Full QTFs diagonal corrected & $0.119 / 8 \%$ & & & $19.0 / 3 \%$ & $17.5 / 2 \%$ & $19.1 / 1 \%$ \\
\hline Experiment & 0.129 & & & 18.5 & 17.1 & 19.0 \\
\hline \multicolumn{7}{|c|}{ Max values/relative error with experiment } \\
\hline Method of calculation & & & & Line $1(N)$ & Line $2(N)$ & Line $3(N)$ \\
\hline Newman's approximation original & & & & $28.9 / 15 \%$ & $26.3 / 16 \%$ & $28.9 / 17 \%$ \\
\hline Newman's approximation corrected & & & & $28.9 / 15 \%$ & $25.9 / 17 \%$ & $28.9 / 17 \%$ \\
\hline Full QTFs & & & & $32.8 / 3 \%$ & $29.7 / 5 \%$ & $29.5 / 16 \%$ \\
\hline Full QTFs diagonal corrected & & & & $33.0 / 3 \%$ & $27.4 / 12 \%$ & $29.5 / 15 \%$ \\
\hline Experiment & & & & 33.9 & 31.2 & 34.9 \\
\hline \multicolumn{7}{|c|}{ Std values/relative error with experiment } \\
\hline Method of calculation & $X(m)$ & $\mathrm{Z}(\mathrm{m})$ & Pitch $\left({ }^{\circ}\right)$ & Line $1(N)$ & Line $2(N)$ & Line $3(N)$ \\
\hline Newman's approximation original & $0.065 / 45 \%$ & $0.053 / 2 \%$ & $7.2 / 16 \%$ & $2.0 / 28 \%$ & $2.1 / 25 \%$ & $2.0 / 30 \%$ \\
\hline Newman's approximation corrected & $0.070 / 41 \%$ & $0.053 / 2 \%$ & $7.2 / 16 \%$ & $2.0 / 28 \%$ & $2.1 / 26 \%$ & $2.0 / 29 \%$ \\
\hline Full QTFs & $0.066 / 44 \%$ & $0.053 / 2 \%$ & $5.6 / 10 \%$ & $2.1 / 23 \%$ & $2.2 / 20 \%$ & $2.1 / 23 \%$ \\
\hline Full QTFs diagonal corrected & $0.066 / 44 \%$ & $0.053 / 2 \%$ & $5.5 / 11 \%$ & $2.1 / 23 \%$ & $2.2 / 21 \%$ & $2.1 / 23 \%$ \\
\hline Experiment & 0.118 & 0.052 & 6.2 & 2.7 & 2.8 & 2.8 \\
\hline
\end{tabular}


Table 12 Comparison of mean and standard deviations between the tank test results and the field test results for the wave elevation, buoy motions and mooring loads. Results are given at the model scale.

\begin{tabular}{|c|c|c|c|c|c|c|}
\hline \multirow{2}{*}{\multicolumn{2}{|c|}{$\begin{array}{l}\text { Wave } \\
\text { Mean field/tank/relative error } \\
\text { Case }\end{array}$}} & \multirow{2}{*}{$\begin{array}{l}\text { Motion } \\
X(\mathrm{~m})\end{array}$} & & \multicolumn{3}{|c|}{ Load in mooring line } \\
\hline & & & & Line $1(N)$ & Line $2(N)$ & Line $3(N)$ \\
\hline 1 & & $-0.388 / 0.129 / 133 \%$ & & $26.6 / 18.5 / 30 \%$ & $25.2 / 17.1 / 32 \%$ & $44.3 / 19.0 / 57 \%$ \\
\hline 2 & & $-0.314 / 0.075 / 124 \%$ & & $23.9 / 18.3 / 23 \%$ & $27.6 / 17.4 / 37 \%$ & $32.9 / 18.6 / 43 \%$ \\
\hline 3 & & $-0.155 / 0.169 / 209 \%$ & & $17.6 / 18.3 / 4 \%$ & $28.1 / 15.5 / 45 \%$ & $60.9 / 18.2 / 70 \%$ \\
\hline \multicolumn{6}{|c|}{ Standard deviation field/tank/relative error } & Line $3(N)$ \\
\hline 1 & $0.059 / 0.054 / 10 \%$ & $0.059 / 0.118 / 100 \%$ & $0.054 / 0.052 / 4 \%$ & $6.2 / 2.7 / 56 \%$ & $10.4 / 2.8 / 73 \%$ & $15.8 / 2.8 / 82 \%$ \\
\hline 2 & $0.030 / 0.028 / 8 \%$ & $0.046 / 0.073 / 57 \%$ & $0.030 / 0.028 / 5 \%$ & $2.9 / 1.7 / 41 \%$ & $5.9 / 2.2 / 63 \%$ & $8.2 / 1.7 / 79 \%$ \\
\hline 3 & $0.085 / 0.077 / 9 \%$ & $0.062 / 0.136 / 120 \%$ & $0.062 / 0.077 / 24 \%$ & $5.3 / 3.3 / 37 \%$ & $10.5 / 3.2 / 70 \%$ & $16.5 / 3.4 / 79 \%$ \\
\hline
\end{tabular}

